\title{
Impact of Pension System Structure on International Financial Capital Allocation
}

\author{
By \\ James Staveley-O'Carroll \\ and \\ Olena M. Staveley-O'Carroll
}

January 2016

COLLEGE OF THE HOLY CROSS, DEPARTMENT OF ECONOMICS FACULTY RESEARCH SERIES, PAPER NO. 16-01*

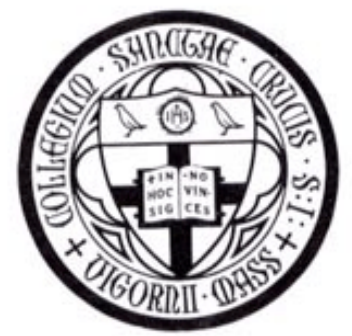

Department of Economics

College of the Holy Cross

Box 45A

Worcester, Massachusetts 01610

(508) 793-3362 (phone)

(508) 793-3710 (fax)

http://www.holycross.edu/academics/programs/economics-and-accounting

*All papers in the Holy Cross Working Paper Series should be considered draft versions subject to future revision. Comments and suggestions are welcome. 


\title{
Impact of Pension System Structure on International Financial Capital Allocation
}

\author{
James Staveley-O'Carroll* \\ Babson College
}

\author{
Olena M. Staveley-O'Carroll ${ }^{\dagger}$ \\ College of the Holy Cross
}

November 8, 2015

\begin{abstract}
Government pension systems vary widely from country to country. Evidence from a cross-section of 110 countries indicates that structural differences in public pension programs are related to reallocation of financial capital around the world. More specifically, we find that greater amounts of pension spending are associated with overall net international indebtedness and a net portfolio characterized by equity assets and debt liabilities. We present a two-country overlapping-generations model that can replicate these empirical regularities and elucidate the link between the structure of pension benefits and the resulting portfolio choices of economic agents. In the country with state-guaranteed pension benefits, workers face a lower overall riskiness of lifetime wealth. As a result, they are willing to invest in risky equity financed by the selling of domestic bonds. Workers in the country with no pension system, on the other hand, tend to be net savers and favor safe debt assets in their portfolios. These findings can help to explain the buildup of global financial imbalances over the last three decades as well as to analyze future changes in capital allocation patterns due to the ongoing pension system reforms in many developing and developed countries.
\end{abstract}

Keywords: global imbalances, international portfolio choice, portfolio risk, pay-as-you-go system, OLG model

JEL Classification: D52, F21, F41, G11, H55

PRELIMINARY AND INCOMPLETE. PLEASE DO NOT CITE OR CIRCULATE

* Corresponding author. Economics Division, Westgate Hall, Babson College, 231 Forest Street, Babson Park, MA 02457. Email: jstaveleyocarroll1@babson.edu

$\dagger$ Department of Economics and Accounting, Box 45A, College of the Holy Cross, One College Street, Worcester, MA 01610. Email: omykhayl@holycross.edu 


\section{Introduction}

It is a well-established fact in the field of international finance that cross-border flows of financial capital and the accompanying current account imbalances in many countries have been on the rise for at least three decades. Following the "savings glut" argument advanced by Bernanke (2005) - suggesting that high savings rates in the developing economies have been driving financial capital into the United States - and the publication of the large-scale database of foreign assets and liabilities by Lane and Milesi-Ferretti (2007), many researchers have become attracted to the detailed examination of the causes of these imbalances. A closer look shows that there are significant differences in the size and composition of international portfolio holdings among different groups of countries: while Asian and oil-exporting countries have been, on average, accumulating (net) international assets, most OECD countries have gone deeper into debt. Many developed countries, including Canada, Italy, and the USA, have debt liabilities offset by equity assets, while the pattern is reversed in, among others, China, Ireland, and Saudi Arabia. Figure 1 demonstrates these trends in the USA, the United Kingdom, and China.
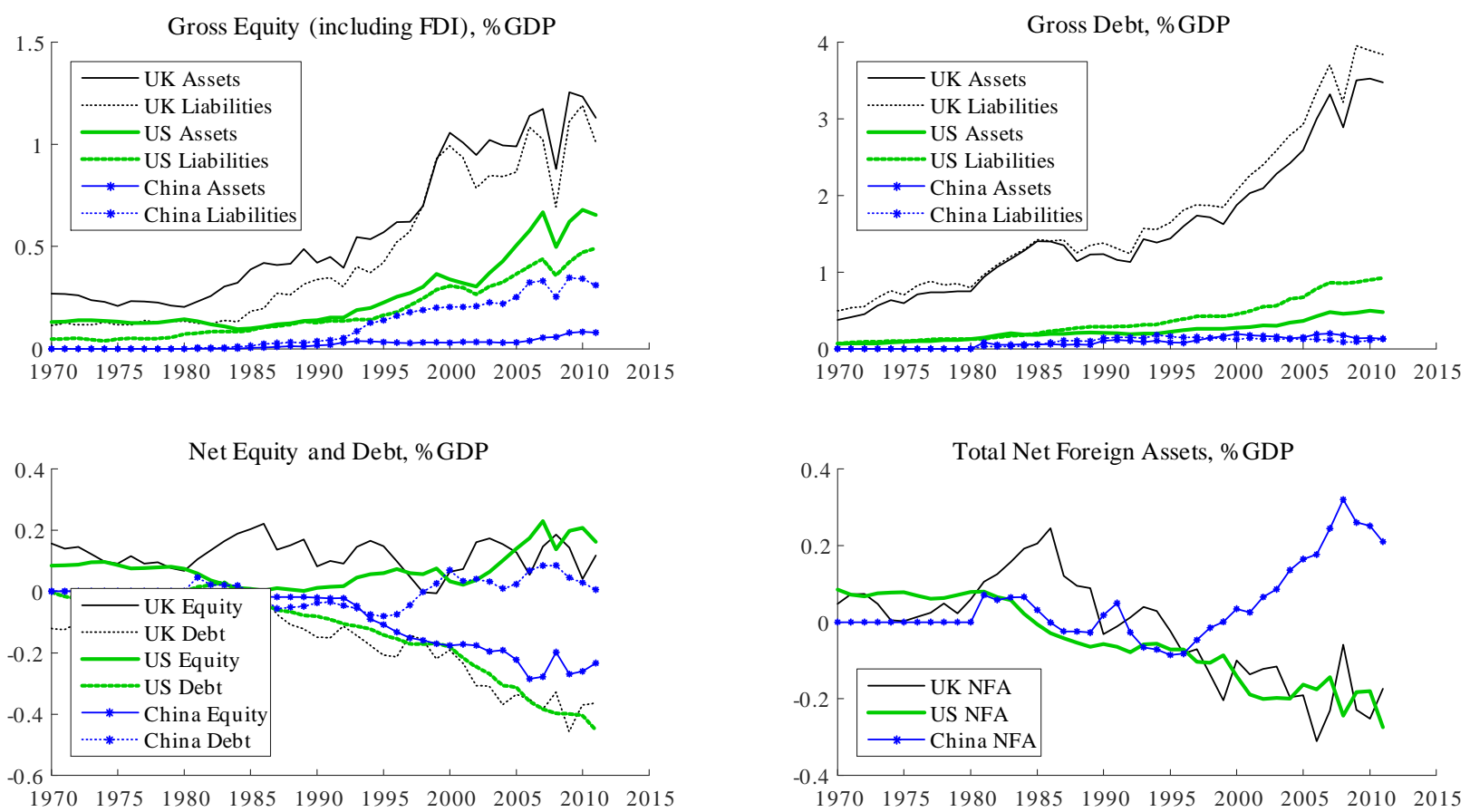

Figure 1: Trends in the stocks of international asset holdings of the UK, the U.S., and China over the past four decades.

The causes of this capital reallocation can be studied in two complementary ways: by focusing on aggregate cross-border financial flows and by examining individual portfolio choices. The former approach has identified many macroeconomic factors driving capital flows into or out of a country, such as exchange rate arrangements, financial liberalization, political and institutional risk, and differences in GDP growth rates $]^{1}$ The latter course

\footnotetext{
${ }^{1}$ Some examples from the large and growing literature include Bacchetta and Wincoop (2000), Gournichas
} 
suggests that lifecycle and precautionary savings motives in the face of the varying degrees of idiosyncratic and aggregate risk, as well as differences in financial instrument availability, can help to explain the growing international imbalances. ${ }^{2}$ Our paper adds to this list by showing that the interaction between personal savings motives and the particular structure of a government-run pension system has a direct impact on the dynamics of international capital flows. This line of inquiry is particularly important in light of the forthcoming demographic changes around the world (increases in longevity and declines in fertility) and the corresponding public policy debates on the sustainability and the need for reform of the pay-as-you-go (PAYG) systems that currently exist in most developed countries. Given the multitude of international linkages among countries, national policies should no longer be examined in a closed economy setting: the international mobility of financial capital will modify the effects of such policies vis-à-vis a world composed of autarkies.

There exists a great deal of heterogeneity in the availability and structure of pension systems around the world, varying along many dimensions such as the degree of coverage (number of workers contributing to the system), replacement rates (ratio of benefits to the average wage), qualifications for receiving pension payments, and the type of funding (pay-asyou-go versus fully funded) $?^{3}$ It is entirely plausible that the particular design of a pension system influences workers' consumption-savings decisions and has a direct impact on the composition of their investment portfolios. In fact, in papers closely related to ours, BörschSupan et al. (2006), Eugeni (2013), and Samwick (2000) demonstrate that the pension system structure has a significant impact on individual savings behavior and through it on the aggregate foreign asset position of a country. More specifically, the latter two papers show that countries with PAYG pension systems tend to be net borrowers. We pursue this line of inquiry further by considering not just the overall net asset position that may result from the pension system asymmetry, but also the particular portfolio composition (debt and equity assets and liabilities).

Based on a cross-section of 110 countries, we find evidence that net equity and net debt positions are influenced by the magnitude of public pension spending; countries with more generous pension systems tend on the net to invest in equity and borrow using debt instruments. Insofar as equity typically carries a higher degree of risk than bonds, higher pension benefits appear to encourage riskier investment strategies. To further test this relationship, we construct a simple measure of portfolio risk, calculated as net equity less net debt relative to a country's gross assets and liabilities. The measure is positive when a country invests in equity and borrows in bonds, and becomes negative in the opposite case; using this metric, we can say that the U.S. has a higher degree of portfolio risk than, for example, China. Empirical analysis of our dataset shows that portfolio risk is positively and statistically significantly related to a country's pension benefits.

Motivated by these empirical regularities, we build a two-country, two-cohort overlapping generations model with internationally traded debt and equity assets to understand

and Rey (2007), Kaminsky and Schmukler (2008), Neumann et al. (2009), Forbes and Warnock (2012), Fratzscher (2012), and de Araujo et al. (2014).

${ }^{2}$ In, for example, Caballero and Krishnamurthy (2006), Devereux (2009), and Mendoza et al. (2009).

${ }^{3}$ Whitehouse (2007), Barr and Diamond (2010), and Social Security Administration's "Social Security Programs Throughout the World," ( http://www.ssa.gov/policy/docs/progdesc/ssptw/, last accessed on 09/16/2014) offer a comprehensive overview of pension system features around the world. 
the relationship between the magnitude of pension guarantees and the resulting portfolio choices of workers. We focus on the PAYG system that characterizes the majority of countries with state pensions, and assume that it is available in one of the two countries (which we subsequently refer to as developed), whereas the workers in the other (developing) economy have to make their own retirement savings arrangements. In their first period of life, consumers in each country earn wages and invest a portion of their earnings into an array of home and foreign equity and bond assets. In the developed country, the government levies a tax on current workers and distributes the proceeds to retirees. During the second (and last) period, the old cohorts simply consume the pension payment and the payout of their period-one portfolio investment. The asymmetry in the pension system availability between the two countries produces three key effects on the composition of consumer portfolios in the model:

1. The gross international assets and liabilities held by both countries rise relative to the benchmark case of no pension system in either economy.

2. The developed country has a lower net foreign asset position than the developing economy.

3. The portfolio risk measure is higher in the developed country, suggesting that a government guarantee of pension benefits encourages riskier portfolio choices by the workers.

The decrease in net foreign assets of the developed country is caused by a change in the holdings of both debt and equity; two mechanisms drive these results. First, the introduction of a PAYG pension system (in the developed economy) generates a very strong wealth effect for the young cohort, which loses a fraction of its current income via the pension tax, but is guaranteed a payment in the next period. Consequently, the workers borrow from abroad (using both equity and debt) to supplement their current consumption, resulting in a negative net foreign asset position of the home country. Second, the defined benefit structure of the retirement system reduces the overall riskiness of the home consumers' lifetime wealth, by replacing risky returns on the stochastic first-period wage income with a governmentguaranteed second-period pension payment. The resulting risk rebalancing effect causes the young home cohort to increase the risk level of its first-period portfolio by financing equity investment through selling of home bonds; this shift is reflected in the higher portfolio risk measure of the home economy.

Given the commonly used calibration of the model parameters, the strength of the wealth effect is much greater than that of the risk rebalancing effect, and home net equity remains negative. By replacing the CRRA preferences in the utility function with Epstein-Zin preferences, we are able to vary consumer attitudes toward within-period risk (and thus the strength of the risk rebalancing effect) separately from their preferences for cross-period consumption smoothing (which control the magnitude of the wealth effect). By increasing the agents' risk aversion and the degree of substitutability between current and future consumption - quite within range of available empirical estimates - we are able to transfer a large share of the risky equity holdings from the foreign to the home household and replicate the aforementioned "venture capitalist" (positive net equity accompanied by negative net debt) portfolio profile of countries with well-established government pension systems. 
In a related line of research, Caballero and Krishnamurthy (2006) show that the growing levels of international debt liabilities of the developed economies (and especially of the U.S.) result from the lack of safe store-of-value assets originating in the developing countries; the latter are therefore forced to seek out U.S. government bonds to diversify their portfolios. We add to this finding by endogenizing the need of less developed economies to seek relatively safe financial assets.

The rest of the paper is organized as follows. The next section presents and discusses some empirical regularities in international data. We then outline the two-country model and describe the links between the government pension guarantees and the resulting portfolio decisions of households. We proceed to report our findings from the model simulations and finally offer some concluding remarks and suggestions for future research.

\section{Estimating the impact of pensions on portfolio deci- sions}

Retirement-income systems around the world are very diverse, varying from non-contributory universal coverage (sometimes known as social) pensions, defined-contribution plans (ranging from unfunded PAYG to fully funded systems) in which the payout depends on a worker's contribution to the system, and voluntary private pension plans; it is quite common to see a combination of several such programs in most economies. The structure, coverage, and replacement rates of a pension system are likely to have a direct impact on the consumptionsavings behavior of households. Although a priori the reaction of the private sector to the structure of the pension systems is ambiguous, cross-country empirical evidence suggests that PAYG systems tend to crowd out private savings (Samwick, 2000; Feldstein and Liebman, 2002). In a theoretical setting, Eugeni (2013) demonstrates that a country with a more advanced pension system will become an international net borrower. Pursuing this line of questioning further, we want to understand the relationship between the structure of a country's pension system and the resulting portfolio decisions (equity and debt borrowing and lending) of the consumers. It is reasonable to hypothesize that, with the promise of generous retirement benefit payouts, an individual during her working years will choose a more risky portfolio of assets (skewed toward equity assets and perhaps even debt liabilities). Conversely, in a country that has a very limited or no pension system, consumers are forced to save for their retirement individually, and therefore will tend to invest in relatively safe assets.

We test this hypothesis by studying the relationship between international capital stocks and pension spending in a cross-section of 110 countries (listed in Appendix C) in 2010. Let $\mathbf{A}=\{N E, N D, N F A\}$ capture the three different measures of international capital stocks: net equity, net debt, and net foreign assets, respectively. Our regression is specified as follows:

$$
Y=\alpha+\beta P S+\gamma^{\prime} \mathbf{X}+\varepsilon
$$

where $Y$ is one of the variables contained in $\mathbf{A}, P S$ captures total pension spending (adjusted for international purchasing power differences), and $\mathbf{X}$ is a vector of control variables defined below; we estimate the model using ordinary least squares. Our main focus is on the sign of 
$\beta$, which measures the directional impact of the size of the pension benefits on the resulting international asset holdings, with the prior that the coefficient is positive for net equity and negative for both net debt and net foreign wealth. Below we briefly describe the three measures of capital stocks and the control variables used in our study; detailed descriptions, sources, and summary statistics of all variables are reported in Appendix C.

The data on international capital holdings are taken from Lane and Milesi-Feretti (2007) Mark II dataset, which contains various annual measures of international debt and equity assets and liabilities for 179 countries between 1970 and 2011. The overall volume of crossborder financial instruments $(G A L)$, measured as the sum of gross assets and liabilities, captures the degree of a country's involvement in the international asset markets. Net equity $(N E)$ and net debt $(N D)$ gauge the degree of riskiness of the portfolio. Finally, net foreign assets $(N F A)$ capture the overall position (positive or negative) of a country vis-à-vis its foreign creditors and debtors.

Estimating equity and debt positions separately, however, paints only a partial picture of the riskiness of a country's international investment position. Therefore, we construct a portfolio risk index $P R$ which measures the general riskiness of a portfolio based on the assumption that equity investments carry more risk than debt assets:

$$
P R=\frac{N E-N D}{G A L}=\frac{(E A-E L)-(D A-D L)}{(E A+E L)+(D A+D L)}
$$

Here $E A, E L, D A$, and $D L$ represent equity assets and liabilities and debt assets and liabilities, respectively. By construction, $P R$, which captures the distributions of net equity and debt in a single variable, ranges from -1 to 1 . At the negative extreme, $P R=-1$ represents the safest portfolio with all liabilities in equity instruments (so that $E A=0$ and $E L>0)$ and all assets in debt instruments $(D A>0$ and $D L=0)$. Conversely, $P R=1$ corresponds to the riskiest portfolio with all assets in equity instruments and all liabilities in debt instruments. Based on our hypothesis, we expect the index to be positively related to the generosity of the pension system.

In our estimation, we control for several other factors that could influence international capital allocations and for additional features of the pension system that can affect consumer portfolio decisions.

The standard approach to analyzing cross-border capital stocks is to measure them relative to GDP. We do not follow this methodology here because countries with low levels of GDP may bias our results. For example, if one billion dollars is transferred from the U.S. to Luxembourg, it counts equally in our measures of both countries' capital holdings. If, on the other hand, we were to measure these stocks as percent of GDP, the transfer would represent less than a hundredth of a percent change in the U.S. international position but more than a two percent change in that of Luxembourg. Thus, expressing asset holdings in relative terms may overstate the importance of small countries in global financial markets and therefore bias our results. ${ }^{4}$ Moreover, Martin and Rey (2004) note that country size, in and of itself, has a positive effect on the number and the variety of assets it produces, and Campos and Kinoshita (2010) find that larger market size (proxied by GDP) does attract more foreign direct investment.

\footnotetext{
${ }^{4}$ Haiti received approximately $\$ 7.5$ billion in aid in the two years since its devastating earthquake in 2010 ; this capital inflow is almost equal to Haiti's annual output.
} 
Generally, we would expect the size of the economy to influence its aggregate saving and borrowing decisions. We include both aggregate GDP (adjusted for purchasing power parity), GDP ppp, and population POP in our set of control variables. Used together, the two variables capture the level of macroeconomic development of a country and the corresponding need for banking services, and also proxy for the strength of its institutions and infrastructure. We include the volume of trade (VOL) in our regressions since, from the balance of payments identity, countries that are more heavily engaged in international trade will necessarily experience a larger flow of cross-border assets. Finally, de Araujo et al. (2014) demonstrate that financial liberalization has a direct impact on the reallocation of financial capital across borders; we therefore include Heritage Foundation's Index of Economic Freedom $(H F I)$ in our regression analysis.

As for other pension system and demographic features that might prove important for the consumption-savings decisions, we include life expectancy of both men and women at birth ( $L E m$ and $L E w)$, the fraction of retirees in total population (RETc), contribution rates $C O N T$ (to pension programs, as a percent of earnings), and the rate of coverage $C O V$, which measures the total number of active contributors relative to the working age population. Higher life expectancy should generally encourage savings (for longer retirement). Controlling for the fraction of retirees addresses the observation that older countries, such as Germany or Japan, tend to be net savers, whereas younger countries, such as India or Mexico, typically have nonzero international debt; see Lane and Milesi-Ferretti (2001) for empirical evidence. Higher contribution and coverage rates are expected to decrease overall savings rates since workers treat expected future pension payouts as a positive wealth effect.

Finally, we identify two subgroups of countries whose idiosyncratic characteristics introduce additional mechanisms driving pension spending and capital accumulation. The nine members of the Organization of the Petroleum Exporting Countries (OPEC) included in our sample have been accumulating net foreign wealth (which many of them have been investing in safe foreign bonds) due to the sharp increase in oil prices that started in the early 2000s. The post-communist Central and Eastern European Countries (CEECs) have inherited pension systems that are much more generous relative to their per capita income that those in the rest of the sample.

Results of all estimations, reported only for the control variables found to be significant in at least one specification, are displayed in Table 1. We find that the effects of pension spending on the composition and riskiness of the countries' portfolios are statistically significant and do support our main conjectures. The only notable exception is the coefficient on the net foreign assets, which has the right sign but is not statistically significant. It is perhaps not surprising that we cannot reproduce exactly the results in Samwick (2000), since - aside from the different sample and time coverage - we are using NFA rather than gross national savings as the dependent variable. Thus, behavior of domestic investment drives a wedge between the two measures and may thereby affect the relationship between retirement payouts and the preferred gauge of savings.

In the next section, we develop a theoretical model that can explain the links between the features of a pension system and the resulting investment-savings decisions of the households. 


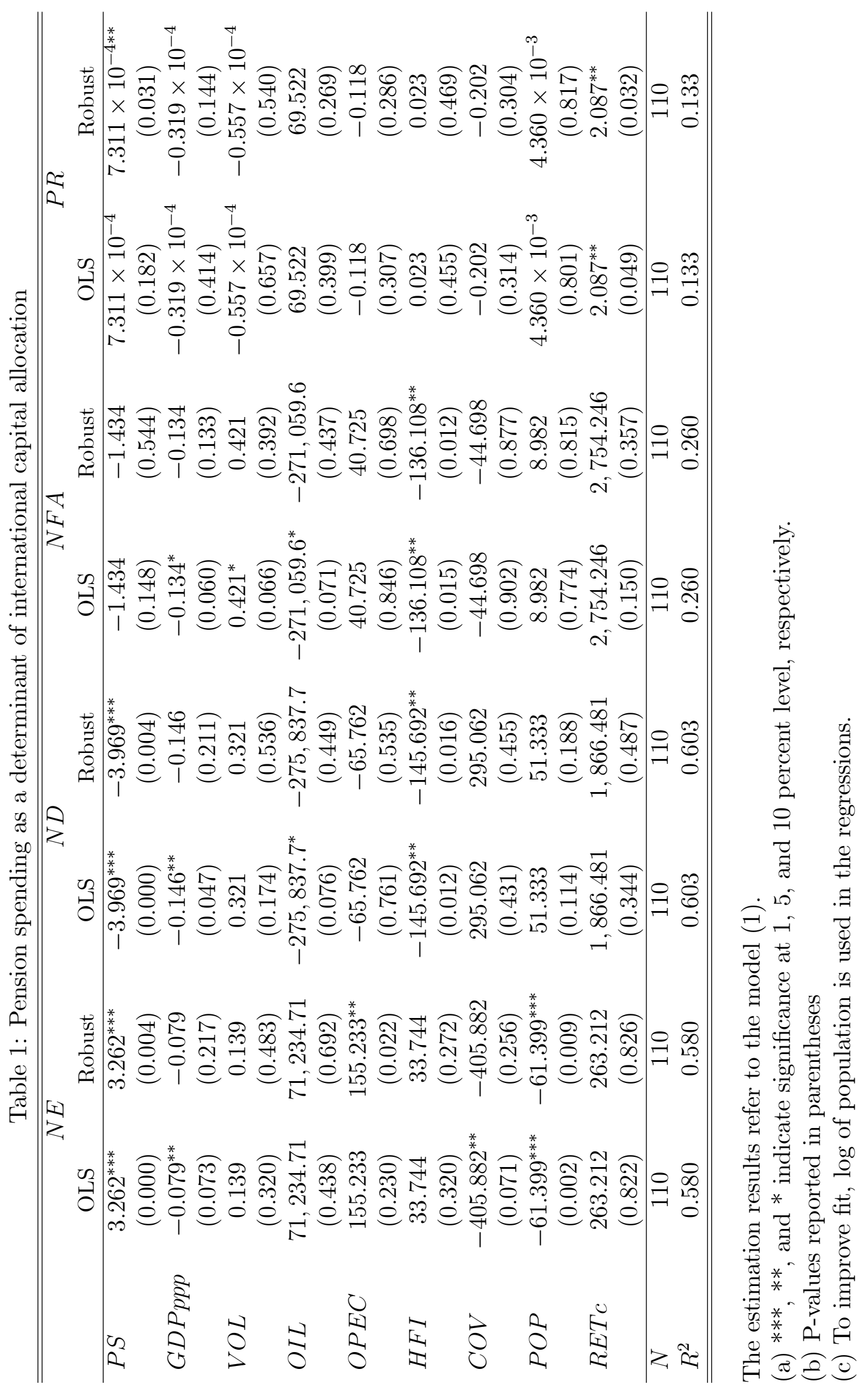




\section{The two-country OLG framework}

At its core, the model contains the following key features necessary to understand the impact of pensions on the international capital allocations: two economies with incomplete financial markets, four internationally-traded assets (two stocks and two bonds), two internationallytraded goods (home and foreign), and two cohorts of consumers (workers and retirees) in each country. Incomplete markets are needed to allow for fluctuations in the distribution of wealth between the two countries, and the menu of four assets allows us to study both gross and net equity and debt positions. The presence of two goods enriches the model environment by adding the real exchange rate adjustment mechanism following country-specific shocks.

The two economies differ only in their pension system setup. The home country has a twotier pension system. In the first tier, the government administers a pure PAYG social security system, in which each period a portion of the workers' stochastic earnings are transferred to the retirees. We consider two versions of the PAYG framework: defined benefit (DB), modeled as a fixed lump-sum tax on the workers, and defined contribution (DC), represented by a fixed proportional tax on wages. Generally (and in our model), there are no investment decisions in pure unfunded PAYG systems and thus asset return risk is absent.5 However, since we require the pension policy to be balanced, so that the taxes are exactly equal to the payouts each period, under the DC setup the income risk to the retirees comes from the income risk of the current generation of workers. The second tier represents fully-funded voluntary private savings. The foreign economy, on the other hand, has only the second tier pensions such that each worker makes individual savings and investment decisions during the working years and collects the corresponding returns upon retirement.

Computing a solution to our model economy is a non-trivial task; therefore, certain aspects of reality that, although potentially important, play no role in our framework. In the model described below we abstract from demographics trends, the role of government debt in supporting the functioning of the pension system, international macroeconomic and institutional asymmetries, and intra-cohort heterogeneity.

It might be helpful, given the somewhat heavy notation needed to describe the model, to note at this stage that in the rest of the paper superscripts are used to denote agentspecific variables (country of residence and period of birth), whereas subscripts will refer to economy-wide indicators such as country of production and the time period.

\subsection{Production}

For simplicity, and to reduce the number of state variables, we model both countries as endowment economies. Perishable output of each country is comprised of wages and dividends,

$$
\begin{aligned}
& y_{h, t}=w_{h, t}+d_{h, t} \\
& y_{f, t}=w_{f, t}+d_{f, t},
\end{aligned}
$$

\footnotetext{
${ }^{5}$ In a partially funded PAYG system, social security tax revenue in excess of pension payments is typically invested in safe assets. For example, in the U.S. the program surplus is placed in the Old-Age and Survivors Insurance (OASI) and Disability Insurance (DI) Trust Funds, which held about $\$ 2.8$ trillion in asset reserves by the end of June 2015. All securities held by the two trust funds must, by law, be issued by the federal government; the trust fund investments earn a market rate of interest.
} 
each of which is in turn determined exogenously by a two-state Markov process. Thus, home wages $w_{h, t}$ can be either low, $W_{h, 1}$, or high, $W_{h, 2}$, and evolve according to the following symmetric transition matrix:

$$
P\left(w_{h, t}=W_{h, 1} \mid w_{h, t-1}=W_{h, 1}\right)=P\left(w_{h, t}=W_{h, 2} \mid w_{h, t-1}=W_{h, 2}\right)=\lambda_{w, h} .
$$

Home dividends, foreign wages, and foreign dividends follow analogous processes with parameters $\left\{D_{h, 1}, D_{h, 2}, \lambda_{d, h}\right\},\left\{W_{f, 1}, W_{f, 2}, \lambda_{w, f}\right\}$, and $\left\{D_{f, 1}, D_{f, 2}, \lambda_{d, f}\right\}$, respectively. We link the two economies by assuming that the two dividend processes are correlated, and use the parameter $\rho_{d, d}=\operatorname{Corr}\left(d_{h, t}, d_{f, t}\right)$ to control the strength of the relationship ${ }^{6}$

The two outputs are combined into aggregate bundles, available for consumption to home and foreign agents, according to the CES aggregators

$$
\begin{aligned}
y_{t}^{h} & =\left[\phi_{h, t}^{1-\sigma}\left(y_{h, t}^{h}\right)^{\sigma}+\left(1-\phi_{h, t}\right)^{1-\sigma}\left(y_{f, t}^{h}\right)^{\sigma}\right]^{\frac{1}{\sigma}} \\
y_{t}^{f} & =\left[\phi_{f, t}^{1-\sigma}\left(y_{f, t}^{f}\right)^{\sigma}+\left(1-\phi_{f, t}\right)^{1-\sigma}\left(y_{h, t}^{f}\right)^{\sigma}\right]^{\frac{1}{\sigma}}
\end{aligned}
$$

and

$$
\begin{aligned}
y_{h, t}^{h}+y_{h, t}^{f} & =y_{h, t} \\
y_{f, t}^{f}+y_{f, t}^{h} & =y_{f, t}
\end{aligned}
$$

The time-varying parameter $\phi_{h, t}\left(\phi_{f, t}\right.$ in the foreign country) captures the extent of home bias in consumption, and $\sigma$ measures the elasticity of substitution between imports and exports. We assume that

$$
\begin{aligned}
\phi_{h, t} & =\phi_{h}+e_{t} \\
\phi_{f, t} & =\phi_{f}+e_{t}
\end{aligned}
$$

where $e_{t}$ is an i.i.d. process with $e_{t} \in\{-e, e\}$.

We define the exogenous state of the economy as $z_{t}=\left\{e_{t}, w_{h, t}, w_{f, t}, d_{h, t}, d_{f, t}\right\}$, which follows a first-order Markov process with finitely many states, $\mathcal{Z}=\left\{z_{1}, \ldots, z_{32}\right\}$.

Given the prices $P_{h, t}$ and $P_{f, t}$, measured in local currency, of the home and foreign output, and assuming that the Law of One Price holds, the two countries' CPIs are

$$
\begin{aligned}
& P_{t}^{h}=\left[\phi_{h, t}\left(P_{h, t}\right)^{\frac{\sigma}{\sigma-1}}+\left(1-\phi_{h, t}\right)\left(S_{t} P_{f, t}\right)^{\frac{\sigma}{\sigma-1}}\right]^{\frac{\sigma-1}{\sigma}} \\
& P_{t}^{f}=\left[\phi_{f, t}\left(P_{f, t}\right)^{\frac{\sigma}{\sigma-1}}+\left(1-\phi_{f, t}\right)\left(S_{t}^{-1} P_{h, t}\right)^{\frac{\sigma}{\sigma-1}}\right]^{\frac{\sigma-1}{\sigma}},
\end{aligned}
$$

where $S_{t}$ is the nominal exchange rate, expressed in units of home currency per one unit of foreign currency. In the rest of the paper, we normalize all home (foreign) prices on the home (foreign) CPI, and refer to them using lower-case letters; we also define the real exchange rate as $q_{t} \equiv \frac{S_{t} P_{t}^{f}}{P_{t}^{h}}, 7$

\footnotetext{
${ }^{6}$ Appendix A describes the relationship between the parameters $\rho_{d, d}, \lambda_{d, h}$, and $\lambda_{d, f}$.

${ }^{7}$ Since we use our model to understand the dynamics of real prices and quantities, we could have alternatively designated the price of, for example, the home good as the numeraire and abstracted from nominal variables altogether. However, allowing each country to have its own currency results in a symmetric solution grid, which simplifies the interpretation of our results.
} 


\subsection{Consumers}

Consumers live for two periods (working years and retirement), and a new generation is born in every period. Consumers are representative within each cohort: the (young) workers born in period $t$ and the (old) retirees born in period $t-1$. We assume zero population growth rate, so that the size of the two cohorts, normalized to unity, is the same in all periods. The young cohort starts with no wealth, earns wages, pays social security taxes (first pillar of the pension system), and saves a portion of its disposable income for retirement (second pillar). The old cohort consumes all of its savings, dividend income, and pension benefits.

The home workers born in period $t$ derive utility from current and future consumption:

$$
U\left(c_{t}^{h, t}, c_{t+1}^{h, t}\right)=\frac{\left(c_{t}^{h, t}\right)^{1-\gamma}}{1-\gamma}+\beta E\left[\frac{\left(c_{t+1}^{h, t}\right)^{1-\gamma}}{1-\gamma}\right]
$$

The superscripts $h$ and $t$ denote the agent's country of residence and period of birth (which also indicates the agent's cohort), and the two consumption bundles $c_{t}^{h, t}$ and $c_{t+1}^{h, t}$ are aggregated from home and foreign goods as in (2).

The workers maximize utility (5) by investing a portion of their disposable wage income into the four available assets. Note that since the old cohort consumes all of its income, the following notation pertains to the asset holdings of the young cohort. Each unit of home (foreign) stock $a_{h, t}\left(a_{f, t}\right)$ with the corresponding price $q_{h, t}\left(q_{f, t}\right)$ entitles its holder to $d_{h, t+1}$ $\left(d_{f, t+1}\right)$ units of the home (foreign) good in the following period. Home (foreign) bonds $b_{h, t}$ $\left(b_{f, t}\right)$, measured in the units of home (foreign) consumption bundles, offer real rates of return equal to $1+r_{h, t}\left(1+r_{f, t}\right)$. We assume that each country has one unit of stock and that both bonds are in zero net supply. The workers choose their period- $t$ consumption $c_{t}^{h, t}$ and the allocations $a_{h, t}^{h, t}, a_{f, t}^{h, t}, b_{h, t}^{h, t}$, and $b_{f, t}^{h, t}$ subject to the following budget constraints:

$$
\begin{aligned}
c_{t}^{h, t}+b_{h, t}^{h, t}+q_{t} b_{f, t}^{h, t}+q_{h, t} a_{h, t}^{h, t}+q_{t} q_{f, t} a_{f, t}^{h, t} & =\Omega_{t}^{h, t}-\kappa I_{t}^{h} \\
c_{t+1}^{h, t} & =\Omega_{t+1}^{h, t}+\kappa I_{t+1}^{h}
\end{aligned}
$$

The period- $t$ wealth $\Omega_{t}^{h, t}$ of the representative worker is equal to her disposable wage:

$$
\Omega_{t}^{h, t} \equiv p_{h, t}\left[\left(1-\tau_{h}\right) w_{h, t}-T_{h}\right]
$$

The government can collect social security contributions from the workers in two ways: as a lump-sum tax $T_{h}$ (restricted to be $T_{h}<w_{h, 1}$ ) or as a fraction $\tau_{h}<1$ of the wage, corresponding to the pure DB and pure DC setups of the PAYG system. In the next section, we consider the two frameworks separately: $T_{h}>0$ and $\tau_{h}=0$ in the first and vice versa in the second. In either case, we assume that the policy is balanced so that in each period the taxes are equal to the transfers given to the old cohort. Thus, each consumer's second period wealth $\Omega_{t+1}^{h, t}$ is the sum of the social security transfers and the payouts of the period- $t$ investments:

$$
\begin{aligned}
\Omega_{t+1}^{h, t} \equiv & \underbrace{p_{h, t+1}\left(\tau_{h} w_{h, t+1}+T_{h}\right)}_{\text {Pension payment }}+ \\
& \underbrace{\left(1+r_{h, t}\right) b_{h, t}^{h, t}+q_{t+1}\left(1+r_{f, t}\right) b_{f, t}^{h, t}+\left(q_{h, t+1}+p_{h, t+1} d_{h, t+1}\right) a_{h, t}^{h, t}+q_{t+1}\left(q_{f, t+1}+p_{f, t+1} d_{f, t+1}\right) a_{f, t}^{h, t}}_{\text {Retuns on financial investments }}
\end{aligned}
$$


Thus, in our model the pension system allows households to share risks across generations and (indirectly, by influencing the young cohort's portfolio choice) across countries. As we demonstrate below, the choice of DB versus DC system is critical for our model's ability to replicate the four empirical trends documented in Section 2; in the presence of stochastic wages, it affects the risk profile of lifetime income differently. In the DB framework, the government collects a fixed amount from the stochastic income of the young cohort and thereby makes the first-period disposable income more volatile while reducing the volatility of the retirees' income. The DC framework, on the other hand, increases the riskiness of the old-cohort income by directly linking it to the workers' fluctuating wages..$^{8}$

We allow agents to go short in all assets; however, to guarantee the compactness of the model state space, we require that their next period wealth $\Omega_{t+1}^{h, t}$ cannot be negative:

$$
\min \Omega_{t+1}^{h, t} \geq 0
$$

This constraint implies that the workers can use their future social security payments as collateral in borrowing. The constraint (10) can also be interpreted as a borrowing constraint on domestic bond holdings $b_{h, t}^{h, t}$ :

$$
\begin{aligned}
b_{h, t}^{h, t} \geq \frac{1}{1+r_{h, t}} \min \left\{p_{h, t+1}\left(\tau_{h} w_{h, t+1}+T_{h}\right)+q_{t+1}\left(1+r_{f, t}\right) b_{f, t}^{h, t}+\right. \\
\left.\quad\left(q_{h, t+1}+p_{h, t+1} d_{h, t+1}\right) a_{h, t}^{h, t}+q_{t+1}\left(q_{f, t+1}+p_{f, t+1} d_{f, t+1}\right) a_{f, t}^{h, t}\right\}
\end{aligned}
$$

Thus, the worker may not borrow more using domestic bonds than her next-period pension payments plus returns on other assets in the worst possible state of nature.

Since compactness restriction (10) allows the starting wealth of the old cohort to be strictly zero (captured by the indicator variable $I_{t}^{h}=1$ ), the uncomfortable implication is that consumption $c_{t+1}^{h, t}$ in equation (7) can be zero as well. To avoid this, we assume that in such a case the government implements a lump-sum relief transfer $\kappa$ from the young to the old generation; it is the model equivalent of the so-called "social pensions," which in many countries guarantee a minimum standard of living to the retired persons. The transfer cannot be used as collateral in borrowing. We set $I_{t}^{h}=0$ if the old cohort's starting wealth $\Omega_{t+1}^{h, t}$ is positive.

The problem of the foreign consumers is analogous, with the exception that $T_{f}=\tau_{f}=0$, eliminating the first PAYG pillar of the pension system. However, the foreign economy has the same "social pension" system $\left(\kappa>0\right.$ for $\left.I_{t}^{f}=1\right)$ to guarantee that the consumption of the old cohort is always positive.

\subsection{Closing the model}

We assume that the monetary authority in each country follows the policy of strict CPI inflation targeting so that

$$
\frac{P_{t+1}^{h}}{P_{t}^{h}}=\frac{P_{t+1}^{f}}{P_{t}^{f}}=1 \quad \forall t
$$

\footnotetext{
${ }^{8}$ Out of 176 national mandatory pension schemes around the world, two thirds may be classified as DB. About half of all the systems operate on an unfunded (or PAYG) basis, with an additional 25 percent being partially funded. (Source: Pallares-Miralles et al., 2012.)
} 
The state of nature of the model economy in period $t$ is given by the beginning-of-period wealth distribution of the two cohorts of retirees, $\Omega_{t}^{h, t-1}$ and $\Omega_{t}^{f, t-1}$, the five exogenous shocks $z_{t}=\left\{e_{t}, w_{h, t}, w_{f, t}, d_{h, t}, d_{f, t}\right\}$, tax policies $T=\left\{T_{h}, T_{f}, \tau_{h}, \tau_{f}, \kappa\right\}$, and monetary policies $M$ given by (12). Given the state of nature, a competitive equilibrium is a price system $P_{t} \equiv\left\{q_{t}, p_{h, t}, p_{f, t}, q_{h, t}, q_{f, t}, r_{r, t}, r_{f, t}\right\}$, an allocation of goods $C_{t} \equiv\left\{c_{t}^{h, t}, c_{t}^{h, t-1}, c_{t}^{f, t}, c_{t}^{f, t-1}\right\}$, and asset positions $A_{t} \equiv\left\{a_{h, t}^{h, t}, a_{h, t}^{f, t}, a_{f, t}^{h, t}, a_{f, t}^{f, t}, b_{h, t}^{h, t}, b_{h, t}^{f, t}, b_{f, t}^{h, t}, b_{f, t}^{f, t}\right\}$ such that

1. given the price system, the allocation and asset positions solve the home and foreign consumers' utility maximization problems, and

2. financial and goods markets clear:

$$
\begin{aligned}
c_{t}^{h, t}+c_{t}^{h, t-1} & =y_{t}^{h} \\
c_{t}^{f, t}+c_{t}^{f, t-1} & =y_{t}^{f} \\
a_{h, t}^{h, t}+a_{h, t}^{f, t} & =a_{f, t}^{h, t}+a_{f, t}^{f, t}=1 \\
b_{h, t}^{h, t}+b_{h, t}^{f, t} & =b_{f, t}^{h, t}+b_{f, t}^{f, t}=0
\end{aligned}
$$

\subsection{Solution method}

The model is solved globally over a compact state-space grid, following the methodology outlined in Stepanchuk and Tsyrennikov (2015). Duffie et al. (1994) show that a unique recursive equilibrium exists in these types of models if the state space is sufficiently rich (in other words, includes enough equilibrium variables to describe the current state of nature).

Even if the model possesses a unique equilibrium, it may be very difficult to solve computationally in the presence of a large number of endogenous state variables (the so-called "curse of dimensionality"). To minimize computational time, we reduce the number of endogenous state variables to one through a series of variable re-definitions. By examining the model's equilibrium equations (listed in Appendix B), we see that the only endogenous state variables are the portfolio choices and their associated prices, contained in the sets $A_{t}$ and $P_{t}$. However, we do not need to keep track of these variables individually; we only need the aggregate value of portfolio holdings of the four agents, which we have already defined as wealth levels $\left\{\Omega_{t}^{h, t}, \Omega_{t}^{h, t-1}, \Omega_{t}^{f, t}, \Omega_{t}^{f, t-1}\right\}$. Moreover, since the young cohort is born into the model without any inherited assets, their wealths $\Omega_{t}^{h, t}$ and $\Omega_{t}^{f, t}$ are determined in period $t$ and therefore need not be carried over as state variables. Thus, we only need to keep track of the evolution of the wealths of the two old cohorts, $\Omega_{t}^{h, t-1}$ and $\Omega_{t}^{f, t-1}$. By combining the two variables, we see that their sum, defined as $\Omega_{t}^{t-1} \equiv \Omega_{t}^{h, t-1}+\Omega_{t}^{f, t-1}$, is also determined contemporaneously based on exogenous states and period- $t$ control variables:

$$
\Omega_{t}^{t-1}=p_{h, t}\left(\tau_{h} w_{h, t}+T_{h}\right)+p_{f, t}\left(\tau_{f} w_{f, t}+T_{f}\right)+\left(q_{h, t}+p_{h, t} d_{h, t}\right)+q_{t}\left(q_{f, t}+p_{f, t} d_{f, t}\right)
$$

Finally, we conclude that the only endogenous state variable we must track across periods is the measure of the distribution of wealth between the retired cohorts:

$$
\omega_{t}^{h, t-1} \equiv \frac{\Omega_{t}^{h, t-1}}{\Omega_{t}^{t-1}}
$$


The borrowing constraint (10) guarantees the compactness of the state space and restricts the wealth ratio $\omega_{t}^{h, t-1}$ to lie within the $[0,1]$ interval.

Given $\omega_{t}^{h, t-1}$ and the exogenous state variables, we can recover the two wealths of the home and foreign old cohorts using (17). The two wealths of the young cohorts and all of the control variables $P_{t}, A_{t}$, and $C_{t}$ can be expressed as functions of the exogenous state $z_{t}$, tax and monetary policies $T$ and $M$, and the one endogenous state variable $\omega_{t}^{h, t-1}$.

We define the state space of the model and the endogenous variables, respectively, as

$$
\begin{aligned}
s_{t} & \equiv\left\{\omega_{t}^{h, t-1}, z_{t}\right\} \\
x_{t} & \equiv\left\{P_{t}, C_{t}, A_{t}\right\}
\end{aligned}
$$

where the sets are contained in the space

$$
\begin{array}{lll}
\mathcal{S} & : & {[0,1] \times \mathcal{Z}} \\
\mathcal{X} & : & R_{+}^{7} \times R_{+}^{4} \times R_{+}^{8}
\end{array}
$$

Additionally, we establish a transition map for the wealth distribution $\omega_{t+1}^{h, t}=\mathcal{O}\left(s_{t}, z_{t+1}\right)$, such that $\mathcal{O}: \mathcal{S} \longrightarrow[0,1]^{32}$. We then use a recursive process to find the optimal policy function $\psi: \mathcal{S} \longrightarrow \mathcal{X}$ such that

$$
\begin{aligned}
0 & =E\left[\Psi\left\{\psi(s), s,\left[\psi\left(s\left(z^{\prime}\right), z^{\prime}\right), s\left(z^{\prime}\right), z^{\prime}\right]_{z^{\prime} \in \mathcal{Z}}\right\} \mid s\right] \\
s\left(z^{\prime}\right) & =\mathcal{O}\left(s, z^{\prime}\right)
\end{aligned}
$$

where $\Psi$ is a system of equilibrium conditions listed in Appendix B. The first of the above two expressions solves the model equations given the current and future state and control variables, and the second is the transition equation for the endogenous state variable $\omega_{t}^{h, t-1}$.

The solution grid is defined over a number of uniform steps, $n$, on the home retirees' wealth ratio $\omega_{t}^{h, t-1}$, such that the step size is $\frac{1}{n-1}$; thus, the grid space is $n \times 32$. At each grid point, we make an initial guess for the policy function $\psi(s)$ and then use B-spline interpolation to approximate the future value of the wealth distribution, $\omega_{t+1}^{h, t}$. The use of homotopy eliminates the possibly of asset returns becoming collinear during the minimization procedure, as outlined by Schmedders (1998), and the Garcia-Zangwill (1981) redefinition of Lagrange multipliers allows for corner solutions when the Euler equations fail to hold. We iterate on the policy function $\psi(s)$ until the difference between the optimal function matrices of the two most recent iterations becomes sufficiently small: $\left\|\psi_{i}(s)-\psi_{i-1}(s)\right\|<10^{-5}$. A detailed description of the solution method can be found in Appendix B.

Given the structural complexity of the portfolio choice problem, the analytical derivation of consumer decision rules is very cumbersome. We instead rely on numerical simulations of the model to uncover the channels that link the national choice of the pension system to the resulting patterns of international capital holdings. We next describe the choice of parameter values used to generate our results.

\subsection{Calibration}

The benchmark specification is described in Table 2; unless otherwise indicated, all parameters describing the foreign economy are identical to the ones in the home country. 
Each period in the model is taken to represent 25 years; thus, we assume that each worker starts his life and career at the age of 25, retires at the age of 50, and lives until the age of 75. We set the intertemporal discount factor $\beta=0.375$; given the $4 \%$ annual real rate of return $(r)$ commonly assumed in the business cycle literature and the 25-year duration of each period in our model $(T)$, the parameter $\beta$ solves $(1+r)^{T}=\beta^{-1}$. We assume log utility by setting $\gamma=1$; however, below we perform a robustness check by increasing the value of this parameter.

We assume that home and foreign goods are imperfect substitutes in consumption, $\sigma=$ $1 / 3$, and let the average home bias parameters be $\phi_{h}=\phi_{f}=0.75$. The degree of trade openness changes by $5 \%$ relative to the average, so that $\left\{e_{1}, e_{2}\right\}=\{-0.05,0.05\}$.

Table 2: Benchmark parameter values

\begin{tabular}{lll}
\hline \hline Parameter & Description & Value \\
\hline$\beta$ & Intertemporal discount factor & 0.375 \\
$\gamma$ & Relative risk aversion coefficient & 1 \\
$\phi_{h}, \phi_{f}$ & Average consumption home bias & 0.75 \\
$\sigma$ & Import/export elasticity of substitution & $1 / 3$ \\
$W_{i, 1}, W_{i, 2}$ & Wage realizations for $i \in\{h, f\}$ & $0.745,1.255$ \\
$D_{i, 1}, D_{i, 2}$ & Dividend realizations for $i \in\{h, f\}$ & $0.257,0.592$ \\
$\lambda_{i, w}$ & Persistence in the wage process for $i \in\{h, f\}$ & 0.522 \\
$\lambda_{i, d}$ & Persistence in the dividend process for $i \in\{h, f\}$ & 0.513 \\
$T_{h}$ & Pension tax, lump sum (with $\left.\tau_{h}=0\right)$ & $\{0.10,0.28,0.47\}$ \\
$\tau_{h}$ & Pension tax, distortionary $\left(\right.$ with $\left.T_{h}=0\right)$ & $\{0.124,0.362,0.599\}$ \\
\hline \hline
\end{tabular}

We use the moments of the annual series for U.S. compensation of employees and capital income (expressed in real per capita terms and HP-filtered) to calibrate the processes for model wages and dividends. To this end, we set $\lambda_{h, w}=0.522$ and $\lambda_{h, d}=0.513$, equivalent to the annual wage and dividend autocorrelations of 0.62 and 0.47 , respectively. We normalize the average wage and dividend in each country to 1 and 0.42 to match the share of capital to labor income in the U.S. Based on this normalization, we set $\left\{W_{h, 1} ; W_{h, 2}\right\}=\{0.745 ; 1.255\}$ and $\left\{D_{h, 1} ; D_{h, 2}\right\}=\{0.257 ; 0.592\}$ to produce the volatilities observed in the data. 9

We consider two different versions of the model: DB, with the lump-sum pension tax $T_{h}>0$ (and $\left.\tau_{h}=0\right)$, and DC with only a distortionary $\operatorname{tax} \tau_{h}>0$ (and $\left.T_{h}=0\right)$. The calibration of the pension taxes and benefits is somewhat convoluted by the assumption that there is an equal number of workers and retirees in our model.

In the DB setup, we can interpret the variable $T_{h}$ as the total pension benefit. According to World Bank HDNSP pensions database, the ratio of pension spending to GDP in the U.S. is 6.8 percent; therefore, we set $T_{h}=0.068 \overline{Y_{h}}=0.10$, where $\overline{Y_{h}}=\frac{1}{2}\left(W_{h, 1}+D_{h, 1}+W_{h, 2}+D_{h, 2}\right)$ is the average realization of home output. This parameterization carries with it the uncomfortable implication that, on average, the benefits per retiree (also described in our model by $T_{h}$ ) are equal to 6.8 percent of income per person (equal to $\overline{Y_{h}}$ ), which of course is much lower

\footnotetext{
${ }^{9}$ Appendix A offers a more detailed explanation of our calibration strategy for wages and dividends. Data sources and descriptions are listed in Appendix C
} 
than in the data. ${ }^{10}$ Alternatively, we can start with the model equilibrium condition that the tax per worker is equal to the benefit per retiree. If we define $a_{h}$ as the ratio of retirees per workers, then $a_{h} T_{h}$ is equal to the total pension benefits. We set $a_{h}=0.207$ equal to the U.S. old-age dependency ratio ${ }^{11}$ and calibrate $T_{h}=\frac{0.068}{0.207} \overline{Y_{h}}=0.47$. Although we better match the retiree benefits at 33 percent of per capita income, the workers in the model now pay the corresponding 33 percent social security income tax. Below we simulate the model using both calibrations, and also consider the average case of $T_{h}=\frac{1}{2}\left(\frac{0.068}{0.207}+0.068\right) \overline{Y_{h}}=0.28$.

In the DC version, we set $\tau_{h}$ equal to the contribution rate for old age, disability, and survivors social security programs, which in the U.S. is equal to 12.4 percent of wage income. ${ }^{12}$ Analogous to the logic of the preceding paragraph, this calibration results in too-low benefits for the retirees. If we instead try to match the latter, we can rescale the tax rate by the dependency ratio and set $\tau_{h}=\frac{0.124}{0.207}=0.599$; in this case, the social security tax levied on the workers is much higher than in the data. We consider both of these calibrations, as well as the average parameterization $\tau_{h}=\frac{1}{2}\left(\frac{0.124}{0.207}+0.124\right)=0.362$.

\section{Impact of pension systems on consumer portfolio choice}

We begin our analysis of the results by simulating the model four times: once with no pension system in either economy (we refer to this as the benchmark specification), and then by considering the three baseline levels of the lump sum social security taxes in the home economy: $T_{h}=\{0.10,0.28,0.47\}$. Each specification is simulated 1,000 times for 1,100 periods starting at the symmetric time-zero cross-country wealth distribution $\Omega_{t}^{h, t}+\Omega_{t}^{h, t-1}=$ $\Omega_{t}^{f, t}+\Omega_{t}^{f, t-1}$; we discard the first 100 time periods so that the initial conditions do not impact the overall results.

Table 3 displays the results of the simulations for the five variables of interest: $G A L^{h} / G D P^{h}$, $N E^{h} / G D P^{h}, N D^{h} / G D P^{h}, N F A^{h} / G P D^{h}$, and $P R^{h}$. We do not report the impact of wage and dividend shocks directly, since our model cannot generate impulse response functions (the shocks have no steady-state or long-run equilibrium values). Instead, the data in the table are generated by computing the average of each variable over the 1,000 periods in each simulation, and then finding the mean and standard deviation of the average across the simulations.

Column 1 of Table 3 describes the benchmark specification; when countries are symmetric in all aspects, consumers do not trade bonds internationally. Cross-border trade in equity is relatively limited as households risk-share internationally only to smooth out country-specific shocks. With the exception of gross asset and liability holdings, all variables of interest are on average not significantly different from zero.

\footnotetext{
${ }^{10}$ According to Whitehouse (2007), the pre-tax and post-tax replacement rates (the percentage of a worker's pre-retirement income paid out by a pension program after retirement) for the average male in the U.S. are 40 and 50 percent, respectively.

${ }^{11}$ The exact definition of the old-age dependency ratio used by the U.S. Social Security administration is $\frac{\text { Population aged } 65 \text { or older }}{\text { Population aged } 18-64}$. Source: The Statistical Abstract of the United States 2012, Table 17 (Age Dependency Ratios by State: 2000 and 2010)

${ }^{12}$ Source: Social Security Administration, "Social Security Programs Throughout the World."
} 
Table 3: Averages of international asset positions of the home economy

\begin{tabular}{lcccc}
\hline \hline & \multicolumn{4}{c}{ Home lump sum tax $\mathbf{T}_{h}$} \\
\cline { 2 - 5 } & $\mathbf{0 . 0 0}$ & $\mathbf{0 . 1 0}$ & $\mathbf{0 . 2 8}$ & $\mathbf{0 . 4 7}$ \\
\hline$G A L^{h} / G D P^{h}$ & 0.1924 & 0.2025 & 0.2194 & 0.2327 \\
& $(0.0008)$ & $(0.0010)$ & $(0.0012)$ & $(0.0013)$ \\
$N E^{h} / G D P^{h}$ & $-0.0011^{b}$ & -0.0073 & -0.0182 & -0.0299 \\
& $(0.0009)$ & $(0.0009)$ & $(0.0009)$ & $(0.0009)$ \\
$N D^{h} / G D P^{h}$ & $0.0000^{b}$ & -0.0144 & -0.0396 & -0.0658 \\
& $(0.0000)$ & $(0.0001)$ & $(0.0003)$ & $(0.0005)$ \\
$N F A^{h} / G P D^{h}$ & $-0.0011^{b}$ & -0.0217 & -0.0578 & -0.0957 \\
& $(0.0009)$ & $(0.0010)$ & $(0.0013)$ & $(0.0014)$ \\
$P R^{h}$ & $0.0026^{b}$ & 0.0411 & 0.1018 & 0.1563 \\
& $(0.0050)$ & $(0.0045)$ & $(0.0035)$ & $(0.0025)$ \\
\hline \hline
\end{tabular}

Notes. (a): Standard errors in parentheses.

(b): all statistics except those marked with the superscript $b$ are significant at the 1 percent level.

We introduce a pension system into (only) the home economy in columns $2-4$. The increase in the lump-sum tax on the workers (and the corresponding increase in the retirees' benefit payments) generates several trends in the simulated data. First, as the consumers in both countries adjust to the asymmetry, gross trade in assets grows in volume. Second, the home households borrow from abroad using both equity and bond instruments. Third, the net foreign assets of the home country become progressively more negative. Finally, the portfolio risk profile indicator $P R^{h}$ of the home economy increases. With the exception of the symmetric benchmark case (in column 1), all statistics reported in Table 3 are significantly different from zero at the 1 percent level.

Before examining the mechanisms behind these trends below, we consider their variability. Table 4 presents the average standard deviation of each variable across the simulations. Two noteworthy regularities emerge from the data as the pension system's size is increased: (1) the higher volatility of the gross and net asset positions $\left(G A L^{h} / G D P^{h}\right.$ and $N F A^{h} / G P D^{h}$, respectively) is driven almost entirely by more volatile bond holdings; and (2) the volatility of portfolio risk profile is inversely related to the magnitude of pension payments. In the next section, we shed some light on the drivers of the international capital movements in our model.

\subsection{Deterioration in the net foreign assets position}

Figure 2 takes a closer look at the home country's net foreign asset position as a function of the social security tax level; more specifically, we plot the four histograms of the variable $N F A^{h} / G D P^{h}$ for the model calibrations considered above. The two reasons for the consistent deterioration in NFA are the wealth effect on the home consumer and the precautionary savings motive of the foreign households. 
Table 4: Volatility of international asset positions of the home economy

\begin{tabular}{lcccc}
\hline \hline & \multicolumn{4}{c}{ Home lump sum tax $\mathbf{T}_{h}$} \\
\cline { 2 - 5 } & $\mathbf{0 . 0 0}$ & $\mathbf{0 . 1 0}$ & $\mathbf{0 . 2 8}$ & $\mathbf{0 . 4 7}$ \\
\hline$G A L^{h} / G D P^{h}$ & 0.0232 & 0.0261 & 0.0312 & 0.0373 \\
& $(0.0004)$ & $(0.0005)$ & $(0.0006)$ & $(0.0007)$ \\
$N E^{h} / G D P^{h}$ & 0.0233 & 0.0225 & 0.0223 & 0.0234 \\
& $(0.0005)$ & $(0.0005)$ & $(0.0004)$ & $(0.0005)$ \\
$N D^{h} / G D P^{h}$ & $0.0000^{b}$ & 0.0028 & 0.0079 & 0.0139 \\
\multirow{2}{*}{$N F A^{h} / G P D^{h}$} & 0.0233 & 0.0249 & 0.0291 & 0.0356 \\
\multirow{2}{*}{$P R^{h}$} & $(0.0005)$ & $(0.0005)$ & $(0.0006)$ & $(0.0008)$ \\
& 0.1215 & 0.1029 & 0.0795 & 0.0644 \\
& $(0.0026)$ & $(0.0023)$ & $(0.0016)$ & $(0.0011)$ \\
\hline \hline
\end{tabular}

Notes. (a): Standard errors in parentheses.

(b): all statistics except those marked with the superscript $b$ are significant at the 1 percent level.

(c): volatility is measured as standard deviation.

The primary mechanism driving domestic dissaving is the wealth effect of the pension system on the young cohort in both the first and the second periods of their lives. During the working period, the home consumer's after-tax wage falls, causing a decrease in the level of current savings (or, more specifically, an increase in current borrowing from abroad). A guaranteed pension payment during the second period of the home worker's life amplifies his desire to borrow as he smooths the increase in the lifetime wealth by transferring some of his future income into the present period. It is worth noting that the ability to use the future expected pension benefits as collateral, captured by (11), increases the home workers' borrowing limit vis-à-vis the unsecured debt case.

At this point it is very important to note that both equity and debt liabilities increase in the same proportion, since we have assumed a constant relative risk aversion (CRRA) utility function. Thus, the pure wealth effect induces a change in the level of the home country's NFA without affecting the overall riskiness of its portfolio. In the next section, we discuss the second effect of the pension system - which we dub the risk-rebalancing effect - that does cause a change in the equity-bonds portfolio composition 13

The second reason for the fall in NFA, well documented in the precautionary savings literature, arises from the international asymmetry itself. Since the foreign consumer does not have access to a state pension system, she must save a portion of her wage income during the first (working) period to ensure nonzero consumption level during the second (retirement) period.

\footnotetext{
${ }^{13}$ In a related paper, Krueger and Kubler (2006) use a closed-economy framework to study the welfare impact of a PAYG system when financial markets are incomplete. The authors reach broadly similar conclusions about the effects of changes in the overall riskiness of lifetime income and of the reduction in workers' disposable income on the resulting savings-consumption patterns.
} 


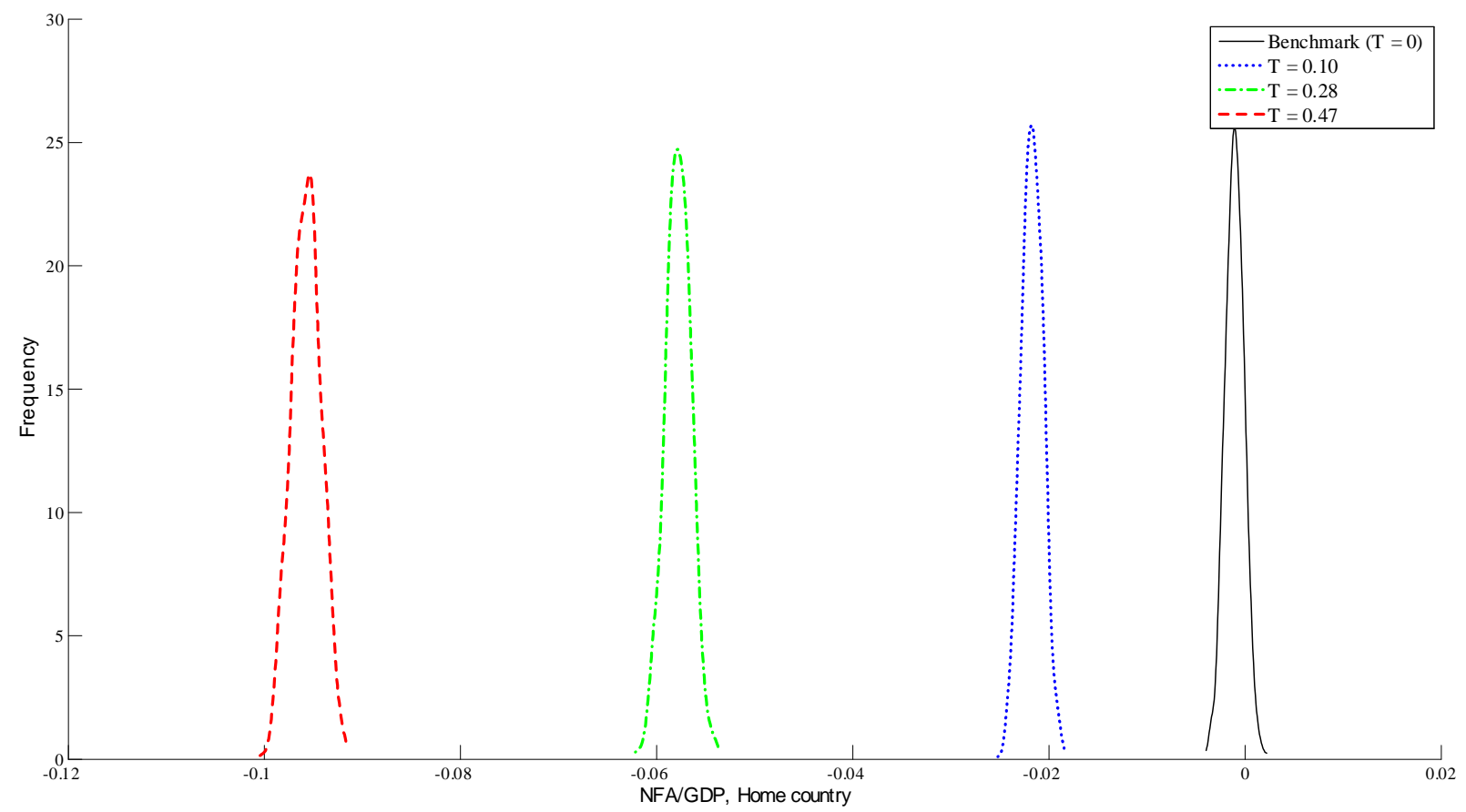

Figure 2: Distribution of the home country's net foreign asset position as a function of the lump-sum social security tax.

\subsection{Increase in portfolio risk profile}

The main contribution of our paper is being able to analyze not just the net flows of capital between countries, but also their composition. Based on the results in Table (3) and illustrated in more detail in Figure 3, the existence of a DB PAYG pension system (as well as the increase in the social security tax $T_{h}$ ) alters the home country's portfolio composition as captured by the risk measure $P R^{h}$, making it progressively more risky.

We hypothesize that the primary reason for the rebalancing of the portfolio towards equity and away from bonds is caused by the change in the level of riskiness of the young cohort's future income, described in equation (9) with $\tau_{h}=0$. As the state-guaranteed pension benefit payment $T_{h}$ increases, the second-period wealth $\Omega_{t+1}^{h, t}$ becomes safer for any given investment choices $\left\{b_{h, t}^{h, t}, b_{f, t}^{h, t}, a_{h, t}^{h, t}, a_{f, t}^{h, t}\right\}$. More importantly, the second-period wealth $\Omega_{t+1}^{h, t}$ of the home workers becomes safer than that of the foreign workers. Since we model both countries as having the same CRRA coefficient $\gamma=1$, the home workers are now willing to take on some additional risk from the foreign workers by increasing the equity investments $a_{h, t}^{h, t}, a_{f, t}^{h, t}$ relative to the benchmark scenario, thereby increasing the price of both home and foreign equities. This international risk rebalancing effect moves home equity asset holdings in the opposite direction from the wealth effect discussed above. Nonetheless, Table 3 shows that the home country's net equity holdings are still negative: the wealth effect outweighs the risk rebalancing effect in magnitude.

We test our hypothesis by performing two robustness checks on the parameters controlling the degree of risk in our model: consumer risk aversion $\gamma$ and the riskiness of the pension 


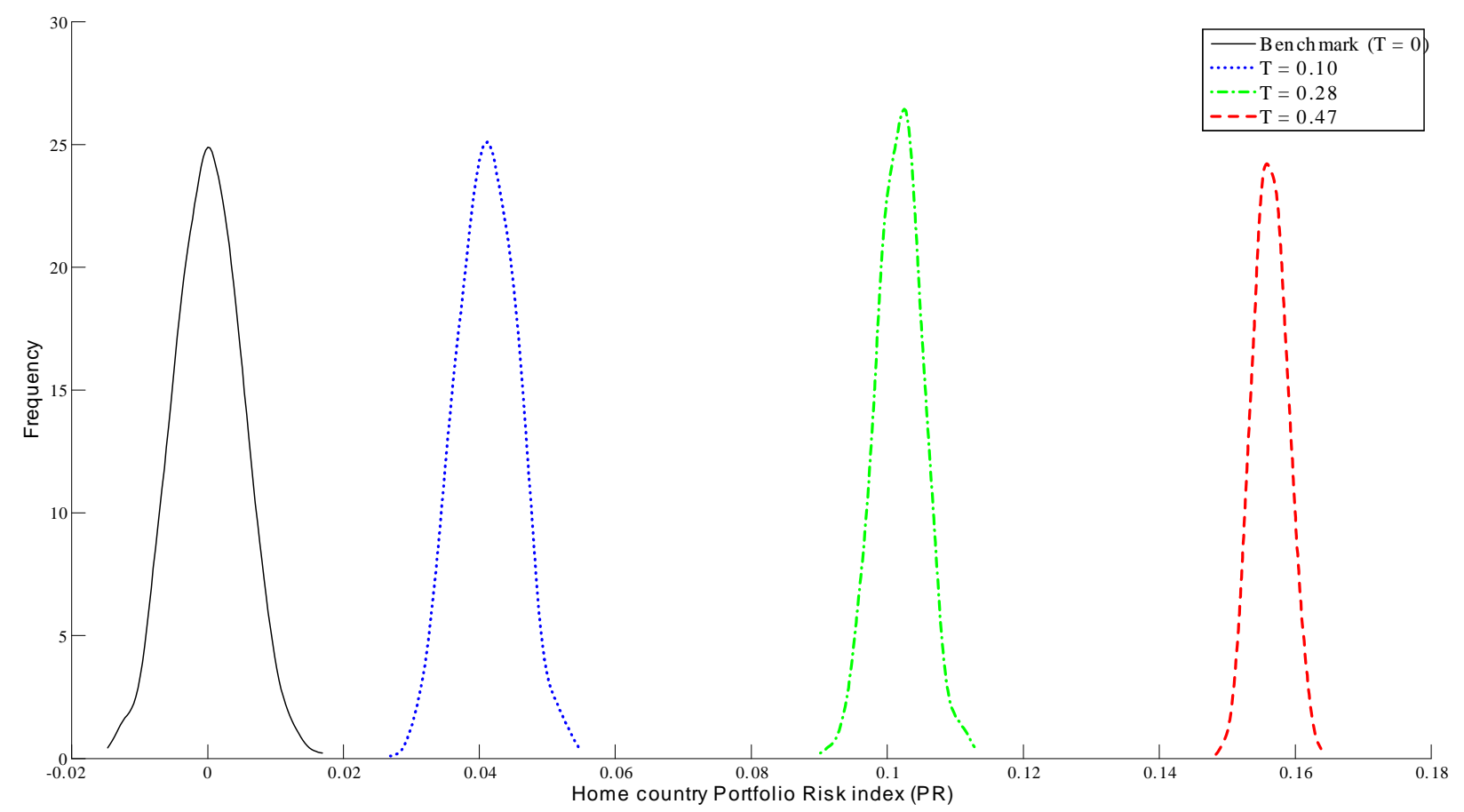

Figure 3: Distribution of the home country's portfolio risk measure as a function of the lump-sum social security tax.

system benefits. For ease of comparison, the first column of Table 5 repeats the results of the baseline simulation with $T_{h}=0.28$. We begin by increasing the CRRA parameter $\gamma$ from 1 to 6 , thus making both countries more risk averse (column 2). This change results in only the portfolio rebalancing effect, since the wealth of the two countries remains unchanged. Therefore, we would expect the foreign workers to be more eager to sell their equity assets and invest the proceeds into the relatively more safe bonds, since their expected future wealth does not have a risk-free component of the government-guaranteed pension payout. The simulations do indeed support our claim: we see an increase in the home portfolio risk $P R^{h}$ from 0.10 to 0.16 as the home households respond to falling equity prices by shifting their investments towards the two stocks and away from bonds. Moreover, the home NFA falls from -5.78 to -6.34 percent as a result of the increase in the precautionary savings by the foreign workers.

The second check involves changing the nature of the pension system from DB to DC. In the model specifications so far, we have assumed that the government finances a riskfree payment to the retirees by garnishing some of the stochastic wage of the workers. It is precisely through this structure that we are able to generate a reduction in the riskiness of the second-period income of the home households. However, this setup only partially resembles the actual structure of PAYG systems: while governments typically guarantee a certain risk-free level of benefits to the pensioners (be it equal across all beneficiaries or linked to their average lifetime earnings), they are financed through distortionary income taxes which fluctuate with business cycles. Any shortfall between pension payouts and tax 
Table 5: Averages of international asset positions of the home economy for different degrees of risk in the model setup.

\begin{tabular}{llll}
\hline \hline & \multicolumn{3}{c}{ Model specification } \\
\cline { 2 - 4 } & $\mathbf{T}_{h}=\mathbf{0 . 2 8}$ & $\boldsymbol{\gamma}=\mathbf{6}$ & $\boldsymbol{\tau}_{h}=\mathbf{0 . 3 6}$ \\
\hline$G A L^{h} / G D P^{h}$ & 0.2194 & 0.2337 & 0.1507 \\
& $(0.0012)$ & $(0.0031)$ & $(0.0009)$ \\
$N E^{h} / G D P^{h}$ & -0.0182 & -0.0120 & -0.0343 \\
& $(0.0009)$ & $(0.0009)$ & $(0.0008)$ \\
$N D^{h} / G D P^{h}$ & -0.0396 & -0.0514 & -0.0356 \\
& $(0.0003)$ & $(0.0007)$ & $(0.0003)$ \\
$N F A^{h} / G P D^{h}$ & -0.0578 & -0.0634 & -0.0699 \\
& $(0.0013)$ & $(0.0014)$ & $(0.0011)$ \\
$P R^{h}$ & 0.1018 & 0.1578 & 0.0162 \\
& $(0.0035)$ & $(0.0025)$ & $(0.0033)$ \\
\hline \hline
\end{tabular}

Notes. (a): Standard errors in parentheses.

(b): all statistics are significant at the 1 percent level.

receipts is financed from previous system savings or by current government borrowing. Due to the computational complexity of solving our model, we only have one endogenous state variable and therefore require the government budget to balance at all times. Thus, the risk-free pension payments must be financed by lump-sum taxes on the young cohort.

To better understand our results, we now completely remove the risk rebalancing effect from the model by changing the lump-sum tax $T^{h}$ to an ad valorem income tax $\tau_{h}$. Now, the pension payments themselves become (counterfactually) risky since they are directly connected to the fluctuating wage rate ${ }^{14}$ As the income transfer from the young to the old cohort no longer reduces the riskiness of the expected future income of home workers and thereby nullifies the risk rebalancing effect, we would expect to see home equity and bond holdings fall in equal proportion as the result of the negative wealth effect of the first-period tax. Column 3 of Table 5 demonstrates exactly that: home workers no longer exhibit a preference for risky versus risk-free assets, and the portfolio risk profile falls by an order of magnitude compared with the baseline case.

It is important to note at this point that even though the DC structure of the pension system makes both parts of the retirees' income volatile, as long as the wage and dividend processes are not perfectly correlated, it pools labor and asset market risks and reduces the consumption variance of the retirees vis-à-vis the fully funded voluntary private savings setup abroad. Therefore, even under the DC specification, the model still generates a marginally risky international portfolio of the home country. This point is further discussed in Shiller (1999) and Bohn (2001, 2009).

Based on the above findings, we can conclude that it is the inherent ability of the PAYG pension systems to reduce the riskiness of the lifetime earning profile that drives the portfo-

\footnotetext{
${ }^{14}$ Since we abstract from modeling labor choice, the ad valorem tax $\tau_{h}$ does not distort the labor market decisions of the young cohort.
} 
Table 6: Additional robustness checks

\begin{tabular}{lccccc}
\hline \hline & \multicolumn{5}{c}{ Model specification } \\
\cline { 2 - 6 } & $T_{h}=0.28$ & $\rho_{d, d}=0.7$ & $\rho_{w, d}=0.457$ & $\sigma=0.8$ & $\phi_{h}=\phi_{f}=0.65$ \\
\hline$G A L^{h} / G D P^{h}$ & 0.2194 & 0.2223 & 0.2190 & 0.2081 & 0.2526 \\
$N E^{h} / G D P^{h}$ & $(0.0012)$ & $(0.0013)$ & $(0.0010)$ & $(0.0014)$ & $(0.0012)$ \\
& -0.0182 & -0.0177 & -0.0186 & -0.0185 & -0.0169 \\
$N D^{h} / G D P^{h}$ & $(0.0009)$ & $(0.0008)$ & $(0.0008)$ & $(0.0010)$ & $(0.0008)$ \\
& -0.0396 & -0.0401 & -0.0401 & -0.0380 & -0.0382 \\
$N F A^{h} / G P D^{h}$ & $(0.0003)$ & $(0.0003)$ & $(0.0003)$ & $(0.0004)$ & $(0.0003)$ \\
& -0.0578 & -0.0578 & -0.0587 & -0.0565 & -0.0551 \\
$P R^{h}$ & $(0.0013)$ & $(0.0011)$ & $(0.0011)$ & $(0.0014)$ & $(0.0010)$ \\
& 0.1018 & 0.1045 & 0.1019 & 0.1041 & 0.0878 \\
\hline \hline
\end{tabular}

Averages of home country's asset positions and portfolio risk. Standard errors reported in parenthesis.

lio reallocation decisions of the workers and thereby exacerbates the net international asset position of many developed economies. We can furthermore hypothesize that fully funded pension systems, in which retirement benefits are linked to the aggregate stock market performance, would offer a much lower incentive for workers to invest in risky equity. Thus, the switch from PAYG to a fully funded system - contemplated in many countries due to growing government debt associated with the shortfall of tax revenue in funding existing pension obligations - could result in significant rebalancing of international portfolios and at least a partial reversal of the recent trends documented in the introduction.

\section{Relative magnitudes of the wealth and the risk-rebalancing effects}

\subsection{Robustness checks of the benchmark model}

To further test our findings, below we conduct four additional robustness checks by varying the values of parameters that can affect the degree of risk (and of risk-sharing) inherent in our model. The results are presented in Table 6, where the first column once again shows, for easier comparison, the results of the baseline calibration with the mid-level home lump-sum $\operatorname{tax} T_{h}=0.28$.

We begin by adding a cross-country correlation to the home and foreign dividend processes; loosely based on the findings in Quinn and Voth (2008), we set the parameter $\rho_{d, d}=0.7$. The change does not produce any statistically significant impact on the simulated net asset positions and on the risk profile of the home economy, as illustrated in column 2 of Table6. We do, however, see a marginal (but statistically significant) increase in the volume of gross assets and liabilities traded between the two economies. Since a positive correlation between 
the home and foreign endowment processes makes riskiness of the two dividend streams more substitutable, they both can be useful in hedging the risk inherent in the stochastic wage process (both at home and abroad).

We also consider the impact of an increase in the within-country correlation between the wage and dividend processes, which we model by setting $\rho_{h}=\rho_{f}=0.457$ based on the corresponding empirical correlation in the U.S. The wage-dividend correlation primarily affects the degree of cross-generational rather than cross-country risk sharing: a positive correlation means higher consumption for both cohorts in good times and vice versa. As discussed in Krueger and Kubler (2006), a social security system improves consumer welfare in the face of imperfectly correlated wages and returns to capital and in the presence of incomplete financial markets by allowing all generations to pool their labor and capital incomes. However, since there are only two generations in our model, they cannot use investment to share income risk with each other (the four assets are only used to share risk across two periods for a particular age cohort). It is, therefore, not surprising that the change in this parameter produces virtually no change on the international portfolio allocations on the home and foreign workers, as reported in column 3.

There is very little agreement in the literature on the appropriate value for the elasticity of substitution between home and foreign goods, $\sigma$. Bodenstein (2010) provides a summary of its recent empirical estimates, which range from -3.55 based on macro-level evidence to 0.83 in micro-level empirical studies. Several recent papers have documented the importance of this parameter for the simulated consumption-real exchange rate correlation and consequently for the degree of international risk-sharing 15 We therefore repeat our simulations by making home and foreign goods more substitutable, captured by the increase in $\sigma$ from its benchmark value of 0.33 to 0.8 . As column 4 demonstrates, our results do depend on this parameter value since most of the dynamics in our model are driven by intertemporal risk-hedging as opposed to intratemporal trade in goods.

Finally, we increase the degree of openness of the two economies by lowering the bias parameter, $\phi$, to 0.65. As shown in the last column of Table 6, the simulated net asset holdings are not significantly affected by this change either. Smaller degree of home bias, similar to an increase in cross-country dividend correlation discussed above, makes home and foreign assets more substitutable. Consequently, gross cross-border asset flows increase in magnitude, and the portfolio risk indicator $P R^{h}$ decreases slightly.

\subsection{Epstein-Zin preferences}

Our benchmark model is able to match three of the four empirical regularities reported in Section 2, it fails to generate the result that countries with more generous social security systems tend to hold long positions in equity assets. The results of the various simulations reported in Tables 36 suggest that the inability of the model to generate a positive $N E^{h}$ value in the home country stems from the too strong wealth effect of the pension system relative to the risk-rebalancing effect. To test this hypothesis and to bring the simulated moments in line with the data, we must be able to more carefully calibrate the strengths of

\footnotetext{
${ }^{15}$ See, among others, Corsetti, Dedola, and Leduc (2008); Enders and Müller (2009); and Mykhaylova and Staveley-O'Carroll (2015).
} 
the two effects.

The strength of the wealth effect - which governs the distribution of the consumer's lifetime earnings across the two periods - depends on the value of the elasticity of intertemporal substitution (EIS). The magnitude of the risk-rebalancing effect, which affects the composition of the consumer's portfolio in the first period, depends on the degree of risk aversion. One of the weaknesses of the CRRA parameterization assumed in the utility function specification (5) is that it conflates the (reciprocal of the) EIS and the degree of relative risk aversion into one parameter $\gamma$. To separate out these two forces, we therefore replace the CRRA preferences in the utility function with Epstein-Zin (EZ) preferences, which allow for a greater degree of flexibility with regard to consumer attitudes toward within-period risk and across-period consumption smoothing:

$$
U\left(c_{t}^{h, t}, c_{t+1}^{h, t}\right)=\left\{\left(c_{t}^{h, t}\right)^{1-\gamma}+\beta E\left[\left(c_{t+1}^{h, t}\right)^{1-\alpha}\right]^{\frac{1-\gamma}{1-\alpha}}\right\}^{\frac{1}{1-\gamma}}
$$

where $\alpha$ controls relative risk aversion and $\gamma$ represents the inverse of the EIS. This new utility function results in a different stochastic discount factor:

$$
m_{t+1}^{h, t}=\beta\left(\frac{c_{t+1}^{h, t}}{c_{t}^{h, t}}\right)^{-\gamma}\left\{\frac{c_{t+1}^{h, t}}{E\left[\left(c_{t+1}^{h, t}\right)^{1-\alpha}\right]^{\frac{1}{1-\alpha}}}\right\}^{\gamma-\alpha}
$$

A greater value of $\alpha$ increases the degree of discounting whenever future consumption is expected to be highly volatile. Setting $\gamma<1(>1)$ makes current and future consumption substitutes (complements). Note that when $\alpha=\gamma$, the preferences are equivalent to CRRA.

The growing interest in the Epstein-Zin utility function in macroeconomics and finance literature stems from its success in fitting asset return and term premium data. $\sqrt{16}$ Since the first-order linearizations of EZ and CRRA preferences are the same, models equipped with the former can easily match empirical business cycle moments. These macroeconomic moments are generally unaffected by the additional higher-order terms introduced by the EZ preferences, allowing for an additional degree of freedom in matching asset price dynamics. Our solution method does not require linearization and therefore can fully capture the added impact of risk aversion modeled independently from the intertemporal elasticity of substitution.

There is not yet a consensus in the literature on the empirical estimates of the EpsteinZin preference parameters $\gamma$ and $\alpha$. The former ranges from 0.5 in Chen et al. (2013) to 10 in Guvenen (2009), and the latter varies from 3 in Li and Smetters (2010) and Amisano and Tristani (2010) to 930 in Paries and Loublier (2010). Therefore, below we repeat our calculations from the previous section for several values of these parameters.

Changing the value of one or both of the EZ parameters affects the model outcomes by changing the strength of the risk rebalancing effect. Table 7 shows the results of our

\footnotetext{
${ }^{16}$ A non-exhaustive list of papers in this field includes Bansal and Yaron (2004), Chen et al. (2013), Guvenen (2009), and Rudebusch and Swanson (2012).
} 
simulations; we use the DB pension setup with the mid-level value of the lump-sum tax, $T_{h}=0.28$, in all specifications. For ease of comparison, the first column displays the results of the baseline specification (the CRRA utility function) discussed previously. We begin by considering the impact of higher risk aversion, while keeping the EIS constant, on the agents' portfolio choices, shown in columns 3 and 4 of Table 7 .

As consumers become more risk averse, ceteris paribus they wish to hold less of risky equity; this drives down its price and increases the equity premium. The asymmetry in the overall riskiness of the lifetime income between home and foreign agents, created by the existence of the pension system in the home country, leads the home consumers to take on a larger share of the portfolio risk from the foreign agents (as discussed in Section 4). The only difference here is the magnitude of the portfolio reallocation: lower equity prices allow home consumers to purchase more equity from foreigners than in the baseline specification (compare columns 2 and 4 of Table 7). Home net equity holdings increase while net debt decreases; overall, home portfolio risk rises from 10 to 17 percent as $\alpha$ increases from 1 to 60. Nonetheless, the increase in net equity in not enough to make it a positive quantity.

The last two columns of Table 7 illustrate the impact of an increase in the EIS on the international capital holdings, which turns out to be nonlinearly related to the degree of risk aversion $\alpha$. When risk aversion is low (column 5, $\alpha=2$ ), making current and future consumption more substitutable produces only a very small effect on the holdings of net equity. In fact, net equity appears to fall, but not by enough to make the change statistically significant. Conversely, when risk aversion is high (column 6, $\alpha=60$ ), an increase in EIS produces a large and significant impact on portfolio composition. In this specification, net equity rises enough to become positive.

The reason why changes in EIS produce a larger impact when risk aversion is high is that agents who take on risk may find their future consumption very different from their current consumption. When substitutability between current and future consumption is low, consumers wish to avoid large swings in the level of their consumption; therefore, everything else being equal, they prefer to invest in safe rather than risky assets (compare columns 3 and $5)$. On the other hand, when substitutability is relatively high $(\gamma=0.5)$, agents care much less about intertemporal consumption smoothing and can take advantage of the low equity prices (generated by an increase in the degree of risk aversion) by taking on the foreigners' portfolio risk and enjoying higher future returns (columns 4 and 6).

Although still subject to some debate, several recent papers have estimated the magnitude of EIS to be 0.5: Chen et al. (2013), van Binsbergen et al. (2012), and Gruber (2006). Setting $\alpha=60$ puts us in the conservative end of the estimated range of this parameter reported in, for example, Chen et al. (2013), van Binsbergen et al. (2012), and Rudebusch and Swanson (2012). Therefore, we can conclude that, for a reasonable parameterization of the EZ utility function, our model is able to replicate and explain all four of the empirical regularities in the international capital holdings data, reported in the beginning of the paper.

\section{Conclusions and extensions}

Motivated by the empirical finding that the magnitude of pension payments induces a sizeable and statistically significant reallocation of capital around the globe and a change in the 
Table 7: Epstein-Zin preferences

\begin{tabular}{lccccc}
\hline \hline & \multicolumn{5}{c}{ Model specification: $(\alpha, \gamma)$} \\
\cline { 2 - 6 } & $(1,1)$ & $(2,1)$ & $(60,1)$ & $(2,0.5)$ & $(60,0.5)$ \\
\hline$G A L^{h} / G D P^{h}$ & 0.2194 & 0.1906 & 0.3429 & 0.2009 & 0.3522 \\
$N E^{h} / G D P^{h}$ & $(0.0012)$ & $(0.0010)$ & $(0.0015)$ & $(0.0010)$ & $(0.0013)$ \\
& -0.0182 & -0.0182 & -0.0015 & -0.0190 & 0.0071 \\
$N D^{h} / G D P^{h}$ & $(0.0009)$ & $(0.0009)$ & $(0.0006)$ & $(0.0010)$ & $(0.0003)$ \\
& -0.0396 & -0.0405 & -0.0597 & -0.0420 & -0.0599 \\
$N F A^{h} / G P D^{h}$ & $(0.0003)$ & $(0.0003)$ & $(0.0006)$ & $(0.0004)$ & $(0.0007)$ \\
& -0.0578 & -0.0587 & -0.0612 & -0.0610 & -0.0527 \\
$P R^{h}$ & $(0.0013)$ & $(0.0012)$ & $(0.0012)$ & $(0.0013)$ & $(0.0010)$ \\
& 0.1018 & 0.1225 & 0.1696 & 0.1197 & 0.1900 \\
& $(0.0035)$ & $(0.0039)$ & $(0.0002)$ & $(0.0040)$ & $(0.0007)$ \\
\hline \hline
\end{tabular}

Averages of home country's asset positions and portfolio risk. Standard errors reported in parenthesis.

international risk profile of the countries in our sample, we build a two-country overlapping generations model to understand the impact of pension system asymmetries on cross-country portfolio holdings. The pension system in the home country is modeled as a direct pay-asyou-go transfer from the young cohort, which earns a stochastic wage and invests a portion of its earnings into several internationally-traded assets, to the old cohort, which consumes all of its investment portfolio returns and the pension payment.

Based on the results of the model simulations, we demonstrate that the existence of a pay-as-you-go pension system impacts both the net foreign asset position and the portfolio risk profile of the home country. The wealth effects of the system on the young and the old cohorts cause both the net equity and net debt holdings of the home country to fall, resulting in a negative net foreign asset position. Additionally, by reducing the riskiness of the future expected income of the young generation, the introduction of the defined benefit pension system encourages the workers to finance their equity investments by borrowing from abroad using debt instruments. As a result, the overall risk profile of the home country's international portfolio increases significantly. However, since the wealth and the risk rebalancing effects move home equity investment in opposite directions, the overall net equity position of the home economy depends on the relative strength of the two channels. By adding reasonably calibrated Epstein-Zin preferences to the model, we are able to replicate and explain all four of the empirical regularities in the patterns of international allocation capital observed in the data, including the "venture capitalist" (positive net equity accompanied by negative net debt) portfolio profile of the United States. More broadly, our finding that countries with larger pension systems tend to have a negative net foreign asset position and a relatively riskier portfolio composition are robust to changes of several parameter values that affect the degree of riskiness and of risk-sharing in the model.

In the age of growing globalization, countries can no longer ignore the international implications of national policies. In a broader sense, our model demonstrates that national 
social security systems are indirectly enabling agents to share risks internationally. While we leave welfare comparisons to future work, it is interesting to note that back-of-the-envelope calculations in Shiller (1999) suggest that welfare gains of this cross-border risk-sharing are much larger than those of the traditional intergenerational risk-sharing typically associated with PAYG systems.

One of the limitations of our framework, necessitated by the computational complexity of the model solution, is the assumption of the balanced government budget. In reality, timevarying tax collections can be supplemented by government borrowing to finance the existing pension payments that are by design independent of business cycles. It is also important to generalize our findings to a setting with a dynamic demographic profile. Given a particular structure of the government pension system, current workers are likely to condition their savings choices on the relative size of the younger (children's) cohort, since the latter's future labor income can determine the generosity of the pension payments to their parents. We leave the two extensions to future research. Equipped with these additional features, our model can then be used to address the very interesting and important question of the impact on the ongoing pension reform in China and India (as well as of the inevitable change in the U.S. Social Security system) on the reallocation of financial capital across the globe. The framework can also be helpful in analyzing global capital reallocation that would result from the switch, contemplated by many developed and developing economies, from PAYG to fully funded pension systems. 


\section{References}

[1] de Araujo, P., Mykhaylova, O., Staveley-O'Carroll, J., 2015. Financial liberalization and patterns of international portfolio holdings. Empirical Economics, 49, 213-234.

[2] Amisano, G., Tristani, O., 2010. A DSGE model of the term structure with regime shifts. Working Paper.

[3] Bacchetta, P., van Wincoop, E., 2000. Capital flows to emerging markets: liberalization, overshooting and volatility. In: Edwards, S. (ed.), Capital flows and the emerging economies: theory, evidence, and controversies. The University of Chicago Press, Chicago, 61-98.

[4] Bansal, R., Yaron, A., 2004. Risks for the long run: a potential resolution of asset pricing puzzles. The Journal of Finance, 59, 1481-1509.

[5] Barr, N., Diamond, P., 2010. Pension Reform in China: Issues, Options and Recommendations. Report prepared as part of the China Economic Research and Advisory Programme.

[6] Bernanke, B., 2005. The global saving glut and the U.S. current account deficit. Speech delivered for the SandridgeLecture at theVirginia Association of Economists, Richmond, March 10, http://www.federalreserve.gov/boarddocs/speeches/2005/200503102/

[7] van Binsbergen, J., Fernández-Villaverde, J., Koijen, R., Rubio-Ramírez, J., 2012. The term structure of interest rates in a DSGE model with recursive preferences. Journal of Monetary Economics, 59, 634-648.

[8] Bodenstein, M., 2010. Trade Elasticity of Substitution and Equilibrium Dynamics. Journal of Economic Theory, 145, 1033-1059.

[9] Bohn, H., 2001. Social security and demographic uncertainty: the risk sharing properties of alternative policies. In Campbell, J. and Feldstein, M., eds, Risk aspects of investment based social security reform. Chicago: University of Chicago Press, 2001, Chapter 6.

[10] Bohn, H., 2009. Intergenerational risk sharing and fiscal policy. Journal of Monetary Economics, 56, 805-816.

[11] Börsch-Supan, A., Ludwig, A., Winter, J., 2006. Ageing, pension reform and capital flows: A multi-country simulation model. Economica, 73, 625-658.

[12] Caballero, R., Krishnamurthy, A., 2006. Bubbles and capital flow volatility: causes and risk management. Journal of Monetary Economics, 53, 35-53.

[13] Campos, N., Kinoshita, Y., 2010. Structural reforms, financial liberalization, and foreign direct investment. IMF Staff Papers, 57, 326-365.

[14] Chen, X., Favilukis, J., Ludvigson, S., 2013. An estimation of economic models with recursive preferences. Quantitative Economics, 4, 39-83. 
[15] Corsetti, G., Dedola, L., Leduc, S., 2008. International risk sharing and the transmission of productivity shocks. Review of Economic Studies, 75, 443-473.

[16] Devereux, M., 2009. A simple model of emerging market portfolio structure. International Review of Economics and Finance, 18, 457-468.

[17] Duffie, D. Geanakoplos, J., Mas-Colell, A., McLennan, A., 1994. Stationary Markov equilibria. Econometrica, 62, 745-781.

[18] Enders, Z., Müller, G., 2009. On the international transmission of technology shocks. Journal of International Economics, 78, 45-59.

[19] Eugeni, S., 2013. An OLG model of global imbalances. The University of York Discussion Papers in Economics No. 13/05.

[20] Feldstein, M., Liebman, J., 2002. Social security. In: Auerbach, A., Feldstein, M. (Eds.) Handbook of Public Economics, Chapter 32, Volume 4, 2246-2324, Elsevier.

[21] Forbes, K.,Warnock, F., 2012. Capital flow waves: surges, stops, flight and retrenchment. Journal of International Economics, 88, 235-251.

[22] Fratzscher, M., 2012. Capital flows, push versus pull factors and the global financial crisis. Journal of International Economics, 88, 341-356.

[23] Garcia, C., Zangwill, W., 1981. Pathways to solutions, fixed points, and equilibria. Prentice Hall, Englewood Cliffs.

[24] Gourinchas, P.-O., Rey, H., 2007. From World Banker to World Venture Capitalist: US External Adjustment and The Exorbitant Privilege, in: Clarida, R. (Ed.), G7 Current Account Imbalances: Sustainability and Adjustment, The University of Chicago Press.

[25] Gruber, J., 2006. A tax-based estimate of the elasticity of intertemporal substitution. NBER Working Paper No. 11945.

[26] Guvenen, F., (2009). A parsimonious macroeconomic model for asset pricing. Econometrica, 77, 1711-1750.

[27] Kaminsky, G., Schmukler, S., 2008. Short-run pain, long-run gain: financial liberalization and stock market cycles. Review of Finance, 12, 253-292.

[28] Krueger, D., Kubler, F., 2006. Pareto-improving social security reform when financial markets are incomplete!? American Economic Review, 96, 737-755.

[29] Lane, P., Milesi-Ferretti, G., 2001. Long-term capital movements. NBER Macroeconomics Annual 2001, 16, 73-136.

[30] Lane, P., Milesi-Ferretti, G., 2007. The external wealth of nations mark II: Revised and extended estimates of foreign assets and liabilities, 1970-2004. Journal of International Economics, 73, 223-250. 
[31] Li, J., Smetters, K., 2010. Optimal portfolio choice over the life cycle with Epstein-ZinWeil preferences and G-and-H distribution. NBER Retirement Research Center Paper No. NB10-15.

[32] Martin, P., Rey, H., 2004. Financial super-markets: size matters for asset trade. Journal of International Economics, 64, 335-361.

[33] Mendoza, E., Quadrini, V., Ríos-Rull, J.-V., 2009. Financial integration, financial development, and global imbalances. Journal of Political Economy, 117, 371-416.

[34] Mykhaylova, O., Staveley-O'Carroll, J., 2014. International transmission of productivity shocks with nonzero net foreign debt. The B.E. Journal of Macroeconomics, 14: Iss. 1 (Contributions), 579-624.

[35] Neumann, R., Penl, R., Tanku, A., 2009. Volatility of capital flows and financial liberalization: Do specific flows respond differently? International Review of Economics and Finance, 18, 488-501.

[36] Quinn, D., Voth, H.-J., 2008. A century of global equity market correlations. American Economic Review: Papers and Proceedings, 98, 535-540.

[37] Pallares-Miralles, M., Romero, C., Whitehouse, E., 2012. International patterns of pension provision II: A worldwide overview of facts and figures. Social Protection Discussion Paper No. 70319, the World Bank.

[38] Pariès, M., Loublier, A., 2010. Epstein-Zin preferences and their use in macro-finance models: implications for optimal monetary policy. European Central Bank Working Paper No. 1209.

[39] Rudebusch, G., Swanson, E., 2012. The bond premium in a DSGE model with long-run real and nominal risks. American Economic Journal: Macroeconomics, 4, 105-143.

[40] Samwick, A., 2000. Is pension reform conducive to higher saving? The Review of Economics and Statistics, 82, 264-272.

[41] Schmedders, K., 1998. Computing equilibria in the general equilibrium model with incomplete asset markets. Journal of Economic Dynamics and Control, 22, 1375-1401.

[42] Shiller, R., 1999. Social security and Institutions for intergenerational, intragenerational, and international risk-sharing. Carnegie-Rochester Conference Series on Public Policy, 50, 165-204.

[43] Stepanchuk, S., Tsyrennikov, V., 2015. Portfolio and welfare consequences of debt market dominance. Journal of Monetary Economics, 74, 89-101.

[44] Whitehouse, E., 2007. Pensions panorama: Retirement-income systems in 53 countries. World Bank Publications, The World Bank, number 7177. 


\section{A Calibrating the wage and dividend processes}

\section{A.1 Moments of time-aggregated series}

Suppose a time series process $\left\{y_{t}\right\}$ is given by

$$
y_{t}=\rho_{y} y_{t-1}+\varepsilon_{y, t}
$$

where $\left\{\varepsilon_{y, t}\right\}$ is white noise distributed as $N\left(0, \sigma_{\varepsilon, y}\right)$. By rewriting process (A.1) in its moving average form $y_{t}=\varepsilon_{y, t}+\rho_{y} \varepsilon_{y, t-1}+\ldots$ we obtain $\operatorname{Var}\left(y_{t}\right)=\frac{\sigma_{\varepsilon, y}^{2}}{1-\rho_{y}^{2}}$. We now want to calculate the variance and autocorrelation of a time-aggregated process $\left\{Y_{\tau}\right\}$, where $Y_{\tau}$ is an $n$-period sum of $y_{t}$ 's: $Y_{\tau}=y_{t}+y_{t+1}+\ldots+y_{t+(n-1)}$. In this appendix, we will use Roman subscripts $t$ to denote annual series and Greek subscripts $\tau$ when referring to the 25-year aggregated sums.

Starting with the simplest case of $n=2$, we compute

$$
\operatorname{Corr}\left(Y_{\tau}, Y_{\tau+1}\right)=\operatorname{Corr}\left(y_{t}+y_{t+1}, y_{t+2}+y_{t+3}\right)
$$

which, recursively substituting A.1), is equal to

$$
\operatorname{Corr}\left(Y_{\tau}, Y_{\tau+1}\right)=\operatorname{Corr}\left[\left(1+\rho_{y}\right) y_{t}+\rho_{y} \varepsilon_{t+1},\left(\rho_{y}^{2}+\rho_{y}^{3}\right) y_{t}+\left(\rho_{y}+\rho_{y}^{2}\right) \varepsilon_{t+1}+\rho_{y} \varepsilon_{t+2}+\varepsilon_{t+3}\right] .
$$

After simplifying the above expression and following the rules of mathematical induction for $n>2$, we obtain

$$
\operatorname{Corr}\left(Y_{\tau}, Y_{\tau+1}\right)=\frac{\rho_{y}\left(\sum_{i=1}^{n} \rho_{y}^{i-1}\right)^{2}}{n+2 \sum_{i=1}^{n-1}(n-i) \rho_{y}^{i}}
$$

Analogously, we can derive the variance of $Y_{\tau}$ :

$$
\operatorname{Var}\left(Y_{\tau}\right)=\frac{\left(n+2 \sum_{i=1}^{n-1}(n-i) \rho_{y}^{i}\right) \sigma_{\varepsilon}^{2}}{1-\rho_{y}^{2}}
$$

Finally, we can also compute the correlation between two processes $\left\{X_{\tau}\right\}$ and $\left\{Y_{\tau}\right\}$, where $X_{\tau}$ is aggregated from $\left\{x_{t}\right\}$ which follows

$$
x_{t}=\rho_{x} x_{t-1}+\varepsilon_{x, t}
$$

with $\left\{\varepsilon_{x, t}\right\} \sim N\left(0, \sigma_{\varepsilon, x}\right)$ and $\operatorname{Corr}\left(x_{t}, y_{t}\right)=\rho$ :

$$
\operatorname{Corr}\left(X_{\tau}, Y_{\tau}\right)=\frac{\rho\left(n+\sum_{i=1}^{n}(n-i)\left(\rho_{x}^{i}+\rho_{y}^{i}\right)\right)}{\left(n+2 \sum_{i=1}^{n-1}(n-i) \rho_{x}^{i}\right)^{0.5}\left(n+2 \sum_{i=1}^{n-1}(n-i) \rho_{y}^{i}\right)^{0.5}}
$$

\section{A.2 Matching the moments to the data}

Appendix C.1 lists the definitions of the time series used below, as well as sources of the data used in our calibration.

Given the empirical labor and capital income (annual) autocorrelations of $\rho_{w}=0.62$ and $\rho_{d}=0.47$, we calculate the autocorrelations of the aggregated (over 25 years) wage and 
dividend series using $(\mathrm{A} .2)$ to be $\operatorname{Corr}\left(W_{\tau}, W_{\tau+1}\right)=0.0438$ and $\operatorname{Corr}\left(D_{\tau}, D_{\tau+1}\right)=0.0254$, respectively. We then use one of the Markov transition matrix properties to solve for $\lambda_{h, w}=$ $\lambda_{f, w}$ from $\operatorname{Corr}\left(W_{\tau}, W_{\tau+1}\right)=2 \lambda_{h, w}-1$; we obtain $\lambda_{h, d}=\lambda_{f, d}$ analogously.

Using A.3), we aggregate the annual standard deviations of $\tilde{w}_{t}$ and $\tilde{d}_{t}$, equal to 2.58 and 4.86 percent, respectively, to obtain $\operatorname{Var}\left(W_{\tau}\right)=0.065$ and $\operatorname{Var}\left(D_{\tau}\right)=0.156$. To solve for the high and low values of the wage, $W_{h, 1}$ and $W_{h, 2}$, we first normalize the average wage realization $\overline{W_{h}} \equiv \frac{1}{2}\left(W_{h, 1}+W_{h, 2}\right)$ to unity. We then solve for $W_{h, 1}$ and $W_{h, 2}$ to match the volatility of the aggregated labor income series:

$$
\frac{\left(W_{h, 1}-\overline{W_{h}}\right)^{2}+\left(W_{h, 1}-\overline{W_{h}}\right)^{2}}{2}=\operatorname{Var}\left(W_{\tau}\right)
$$

We obtain the two dividend realizations, $D_{h, 1}$ and $D_{h, 2}$, analogously, except that we normalize the average dividend $\overline{W_{d}}$ to be 0.42 , to match the average ratio of (unfiltered) per capita real capital to labor income $\frac{w_{t}}{d_{t}}$ in the U.S. data.

Finally, given $\operatorname{Corr}\left(\tilde{w}_{t}, \tilde{d}_{t}\right)=0.448$, we can calculate $\rho_{w, d} \equiv \operatorname{Corr}\left(W_{\tau}, D_{\tau}\right)=0.457$.

Given the above parameters, we model the evolution of the five exogenous shocks in our model, $\left\{W_{h}, W_{f}, D_{h}, D_{f}, e\right\}$ as following a joint Markov transition matrix $\boldsymbol{\Lambda}$ :

$$
\boldsymbol{\Lambda}=\left(\boldsymbol{\Lambda}_{h, w} \otimes \boldsymbol{\Lambda}_{f, w}+\mathbf{R}_{1}\right) \otimes\left(\boldsymbol{\Lambda}_{h, d} \otimes \boldsymbol{\Lambda}_{f, d}+\mathbf{R}_{2}\right) \otimes \boldsymbol{\Lambda}_{e}
$$

where the $2 \times 2$ transition matrices $\boldsymbol{\Lambda}_{i, j}$ control the evolution of each country's wage and (separately) dividends

$$
\boldsymbol{\Lambda}_{i, j}=\left[\begin{array}{cc}
\lambda_{i,, j} & 1-\lambda_{i,, j} \\
1-\lambda_{i,, j} & \lambda_{i,, j}
\end{array}\right] \quad \text { for } i \in\{h, f\} \text { and } j \in\{w, d\},
$$

the home bias shock process is governed by the process $\boldsymbol{\Lambda}_{e}$

$$
\boldsymbol{\Lambda}_{e}=\left[\begin{array}{ll}
0.5 & 0.5 \\
0.5 & 0.5
\end{array}\right]
$$

and the matrices $\mathbf{R}_{1}$ and $\mathbf{R}_{2}$ determine the degree of correlation between the different shocks. In our robustness checks, we consider two specifications of these correlations. In the first, we assume that the two dividend processes are correlated across countries: $\operatorname{Corr}\left(D_{h, \tau}, D_{f, \tau}\right)=$ $\rho_{d, d}$. In this case, $\mathbf{R}_{1}=\mathbf{0}$ and

$$
\mathbf{R}_{2}=\left[\begin{array}{cccc}
\rho_{d, d} & -\rho_{d, d} & -\rho_{d, d} & \rho_{d, d} \\
\rho_{d, d} & -\rho_{d, d} & -\rho_{d, d} & \rho_{d, d} \\
\rho_{d, d} & -\rho_{d, d} & -\rho_{d, d} & \rho_{d, d} \\
\rho_{d, d} & -\rho_{d, d} & -\rho_{d, d} & \rho_{d, d}
\end{array}\right] \frac{\lambda_{h, d}+\lambda_{f, d}-2 \lambda_{h, d} \lambda_{f, d}}{2}
$$

Alternatively, we can assume that within each country, the correlation between wages and dividends is given by $\operatorname{Corr}\left(W_{h, \tau}, D_{h, \tau}\right)=\operatorname{Corr}\left(W_{f, \tau}, D_{f, \tau}\right)=\rho_{w, d}$. Then

$$
\mathbf{R}_{1}=\mathbf{R}_{2}=\left[\begin{array}{cccc}
\rho_{w, d} & -\rho_{w, d} & -\rho_{w, d} & \rho_{w, d} \\
\rho_{w, d} & -\rho_{w, d} & -\rho_{w, d} & \rho_{w, d} \\
\rho_{w, d} & -\rho_{w, d} & -\rho_{w, d} & \rho_{w, d} \\
\rho_{w, d} & -\rho_{w, d} & -\rho_{w, d} & \rho_{w, d}
\end{array}\right] \frac{\lambda_{i, w}+\lambda_{i, d}-2 \lambda_{i, w} \lambda_{i, d}}{2} \text { for } i \in\{h, f\} .
$$




\section{B Solution methodology}

The model is solved globally over a compact state space grid, following the methodology outlined in Stepanchuk and Tsyrennikov (2015). First, we complete the state space as follows:

$$
\begin{aligned}
z_{t} & \equiv\left\{e_{t}, w_{h, t}, w_{f, t}, d_{h, t}, d_{f, t}\right\}: \mathcal{Z} \\
s_{t} & \equiv\left\{\omega_{t}^{h, t-1}, z_{t}\right\}:[0,1] \times \mathcal{Z}
\end{aligned}
$$

Additionally, we define the three sets (prices, consumption, and asset positions) of endogenous control variables:

$$
\begin{aligned}
P_{t} & \equiv\left\{q_{t}, p_{h, t}, p_{f, t}, q_{h, t}, q_{f, t}, r_{r, t}, r_{f, t}\right\}: R_{+}^{7} \\
C_{t} & \equiv\left\{c_{t}^{h, t}, c_{t}^{h, t-1}, c_{t}^{f, t}, c_{t}^{f, t-1}\right\}: R_{+}^{4} \\
A_{t} & \equiv\left\{a_{h, t}^{h, t}, a_{h, t}^{f, t}, a_{f, t}^{h, t}, a_{f, t}^{f, t}, b_{h, t}^{h, t}, b_{h, t}^{f, t}, b_{f, t}^{h, t}, b_{f, t}^{f, t}\right\}: R_{+}^{8}
\end{aligned}
$$

Using the Garcia-Zangwill (1981) redefinition of the Lagrange multiplier allows the model to reach corner solutions

$$
\begin{aligned}
v_{t}^{h,+} & \equiv \max \left\{0, v_{t}^{h}\right\} \\
v_{t}^{f,+} & \equiv \max \left\{0, v_{t}^{f}\right\} \\
v_{t}^{h,-} & \equiv \max \left\{0,-v_{t}^{h}\right\} \\
v_{t}^{f,-} & \equiv \max \left\{0,-v_{t}^{f}\right\}
\end{aligned}
$$

where $v_{t}^{h}$ and $v_{t}^{f}$ are the multipliers on the home and foreign borrowing constraints, respectively. When the multipliers are positive, $v_{t}^{h,+}$ and $v_{t}^{f,+}$ are also positive and $v_{t}^{h,-}$ and $v_{t}^{f,-}$ are zero; on the other hand, when the multipliers are negative, both $v_{t}^{h,-}$ and $v_{t}^{f,-}$ become positive. In none of the model specifications (including the robustness check) do the agents' borrowing constraints bind.

We next solve the system of the model equations for (most of) the endogenous variables in $P_{t}, C_{t}$, and $A_{t}$. The assets market clearing conditions (15) imply that

$$
\begin{aligned}
& a_{h, t}^{f, t}=1-a_{h, t}^{h, t} \\
& a_{f, t}^{h, t}=1-a_{f, t}^{f, t}
\end{aligned}
$$

The definitions of the CPI, (3) and (4), can be used to solve for home and foreign price of goods

$$
\begin{aligned}
& p_{h, t}=\left[\frac{\phi_{f, t}-\left(1-\phi_{h, t}\right)\left(q_{t}\right)^{\frac{\sigma}{\sigma-1}}}{\phi_{h, t}+\phi_{f, t}-1}\right]^{\frac{\sigma-1}{\sigma}} \\
& p_{f, t}=\left[\frac{\phi_{h, t}-\left(1-\phi_{f, t}\right)\left(q_{t}\right)^{\frac{\sigma}{1-\sigma}}}{\phi_{h, t}+\phi_{f, t}-1}\right]^{\frac{\sigma-1}{\sigma}}
\end{aligned}
$$


The definitions of wealth (8) and (9), together with the total wealth of the old cohorts (17), imply that $\omega_{t}^{f, t-1}=1-\omega_{t}^{h, t-1}$. We use the old cohorts' budget constraints to solve for their consumption levels:

$$
\begin{aligned}
c_{t}^{h, t-1} & =\omega_{t}^{h, t-1} \Omega_{t}^{t-1}+\kappa I_{t}^{h} \\
c_{t}^{f, t-1} & =\frac{\omega_{t}^{f, t-1} \Omega_{t}^{t-1}}{q_{t}}+\kappa I_{t}^{f}
\end{aligned}
$$

Furthermore, the goods market clearing conditions, $(13)$ and $(14)$, can be used to find the young cohorts' consumptions levels:

$$
\begin{aligned}
c_{t}^{h, t} & =\frac{1}{\left(\phi_{h, t}+\phi_{f, t}-1\right)}\left[\phi_{f, t}\left(p_{h, t}\right)^{\frac{1}{1-\sigma}} Y_{h, t}-\left(1-\phi_{f, t}\right)\left(q_{t} p_{f, t}\right)^{\frac{1}{1-\sigma}} Y_{f, t}\right]-c_{t}^{h, t-1} \\
c_{t}^{f, t} & =\frac{1}{\left(\phi_{h, t}+\phi_{f, t}-1\right)}\left[\phi_{h, t}\left(p_{f, t}\right)^{\frac{1}{1-\sigma}} Y_{f, t}-\left(1-\phi_{h, t}\right)\left(\frac{p_{h, t}}{q_{t}}\right)^{\frac{1}{1-\sigma}} Y_{h, t}\right]-c_{t}^{f, t-1}
\end{aligned}
$$

We define the stochastic discount factors for each young cohort:

$$
\begin{aligned}
& m_{t+1}^{h, t}=\beta\left(\frac{c_{t+1}^{h, t}}{c_{t}^{h, t}}\right)^{-\gamma} \\
& m_{t+1}^{f, t}=\beta\left(\frac{c_{t+1}^{f, t}}{c_{t}^{f, t}}\right)^{-\gamma}
\end{aligned}
$$

The first order conditions with respect to the home holding of the home bond, $b_{h, t}^{h, t}$, and the foreign holding of the foreign bond, $b_{f, t}^{f, t}$, respectively, are used to find the home and foreign real interest rates:

$$
\begin{aligned}
& r_{h, t}=\left\{E\left[m_{t+1}^{h, t}\right]+v_{t}^{h,-}\left(c_{t}^{h, t}\right)^{\gamma}\right\}^{-1}-1 \\
& r_{f, t}=\left\{E\left[m_{t+1}^{f, t}\right]+v_{t}^{f,-}\left(c_{t}^{f, t}\right)^{\gamma}\right\}^{-1}-1
\end{aligned}
$$

Finally, the home and foreign borrowing constraints are rearranged to solve for $b_{h, t}^{h, t}$ and $b_{f, t}^{f, t}$, respectively:

$$
\begin{aligned}
& b_{h, t}^{h, t}= v_{t}^{h,+}-\frac{1}{\left(1+r_{h, t}\right)} \times \\
& \min \left\{p_{h, t+1}\left(\tau_{h} w_{h, t+1}+T_{h}\right)+q_{t+1}\left(1+r_{f, t}\right) b_{f, t}^{h, t}+\right. \\
&\left.\left(q_{h, t+1}+p_{h, t+1} d_{h, t+1}\right) a_{h, t}^{h, t}+q_{t+1}\left(q_{f, t+1}+p_{f, t+1} d_{f, t+1}\right) a_{f, t}^{h, t}\right\} \\
& b_{f, t}^{f, t}= v_{t}^{f,+}-\frac{1}{\left(1+r_{f, t}\right)} \times \\
& \min \left\{p_{f, t+1}\left(\tau_{f} w_{f, t+1}+T_{f}\right)+\frac{\left(1+r_{h, t}\right)}{q_{t+1}} b_{h, t}^{f, t}+\right. \\
&\left.\frac{\left(q_{h, t+1}+p_{h, t+1} d_{h, t+1}\right)}{q_{t+1}} A_{h, t}^{f, t}+\left(q_{f, t+1}+p_{f, t+1} d_{f, t+1}\right) a_{f, t}^{f, t}\right\}
\end{aligned}
$$


We define the function $\Psi(\cdot)$ as residual of the remaining Euler equations, of the young cohorts' budget constraints (6), and of the home bond market clearing condition (16) (the foreign bond market clearing condition holds by Walras' law):

$$
\begin{aligned}
0 & =E\left[q_{t+1} m_{t+1}^{h, t}\right]+v_{t}^{h,-} \min \left\{q_{t+1}\right\}\left(c_{t}^{h, t}\right)^{\gamma}-\frac{q_{t}}{\left(1+r_{f, t}\right)} \\
0 & =E\left[\left(q_{h, t+1}+p_{h, t+1} d_{h, t+1}\right) m_{t+1}^{h, t}\right]+v_{t}^{h,-} \min \left\{q_{h, t+1}+p_{h, t+1} d_{h, t+1}\right\}\left(c_{t}^{h, t}\right)^{\gamma}-q_{h, t} \\
0 & =E\left[q_{t+1}\left(q_{f, t+1}+p_{f, t+1} d_{f, t+1}\right) m_{t+1}^{h, t}\right]+v_{t}^{h,-} \min \left\{q_{t+1}\left(q_{f, t+1}+p_{f, t+1} d_{f, t+1}\right)\right\}\left(c_{t}^{h, t}\right)^{\gamma}-q_{t} q_{f, t} \\
0 & =E\left[\frac{m_{t+1}^{f, t}}{q_{t+1}}\right]+v_{t}^{f,-} \min \left\{\frac{1}{q_{t+1}}\right\}\left(c_{t}^{f, t}\right)^{\gamma}-\frac{1}{q_{t}\left(1+r_{h, t}\right)} \\
0 & =E\left[\frac{\left(q_{h, t+1}+p_{h, t+1} d_{h, t+1}\right)}{q_{t+1}} m_{t+1}^{f, t}\right]+v_{t}^{f,-} \min \left\{\frac{q_{h, t+1}+p_{h, t+1} d_{h, t+1}}{q_{t+1}}\right\}\left(c_{t}^{f, t}\right)^{\gamma}-\frac{q_{h, t}}{q_{t}} \\
0 & =E\left[\left(q_{f, t+1}+p_{f, t+1} d_{f, t+1}\right) m_{t+1}^{f, t}\right]+v_{t}^{f,-} \min \left\{q_{f, t+1}+p_{f, t+1} d_{f, t+1}\right\}\left(c_{t}^{f, t}\right)^{\gamma}-q_{f, t} \\
0 & =\Omega_{t}^{h, t}-c_{t}^{h, t}-b_{h, t}^{h, t}-q_{t} b_{f, t}^{h, t}-q_{h, t} a_{h, t}^{h, t}-q_{t} q_{f, t} a_{f, t}^{h, t}-\kappa I_{t}^{h} \\
0 & =\frac{\Omega_{t}^{f, t}}{q_{t}}-c_{t}^{f, t}-\frac{b_{h, t}^{f, t}}{q_{t}}-b_{f, t}^{f, t}-\frac{q_{h, t}}{q_{t}} a_{h, t}^{f, t}-q_{f, t} a_{f, t}^{f, t}-\kappa I_{t}^{f} \\
0 & =b_{h, t}^{h}+b_{h, t}^{f}
\end{aligned}
$$

The above nine equations are used to solve for the remaining control variables

$$
\left\{q_{t}, q_{h, t}, q_{f, t}, a_{h, t}^{h, t}, a_{f, t}^{f, t}, b_{f, t}^{h, t}, b_{h, t}^{f, t}, v_{t}^{h}, v_{t}^{f}\right\}
$$

The transition map for the wealth distribution $\mathcal{O}(\cdot)$ is given by

$$
\begin{aligned}
\omega_{t+1}^{h, t}= & \frac{1}{\Omega_{t+1}^{t}}\left[p_{h, t+1}\left(\tau_{h} w_{h, t+1}+T_{h}\right)+\left(1+r_{h, t}\right) b_{h, t}^{h, t}+q_{t+1}\left(1+r_{f, t}\right) b_{f, t}^{h, t}\right. \\
& \left.+\left(q_{h, t+1}+p_{h, t+1} d_{h, t+1}\right) a_{h, t}^{h, t}+q_{t+1}\left(q_{f, t+1}+p_{f, t+1} d_{f, t+1}\right) a_{f, t}^{h, t}\right]
\end{aligned}
$$

The solution grid is defined over the entire state space $\mathcal{S}$ using a number of uniform steps, $n$, on the home retirees' wealth ratio $\omega_{t}^{h, t-1}$, such that the step size is $\frac{1}{n-1}$; thus, the grid space is $n \times 32$. We set $n=11$. An initial guess is selected for the policy functions $\Psi(\cdot)$; B-spline interpolation allows us to approximate future values of the wealth distribution, $\omega_{t+1}^{h, t}$, between the grid points. The use of homotopy eliminates the possibly of asset returns becoming collinear during the minimization procedure outlined in Schmedders (1998). We iterate on the policy function $\psi(w)$ until $\left\|\psi_{i}(w)-\psi_{i-1}(w)\right\|<10^{-5}$.

Five additional grids are required to define future values of $\left\{q_{t+1}, q_{h, t+1}, q_{f, t+1}, c_{t+1}^{h, t}, c_{t+1}^{f, t}\right\}$ over the state $s_{t+1}$. Initial guesses for these grids are calculated using the average values of all five shocks. 


\section{Data sources and description}

\section{C.1 Calibration}

All data are taken from The Bureau of Economic Analysis and refer to the 1947-2013 period annual U.S. variables.

$W_{t}$ : Compensation of employees, paid, billions of dollars. Table 1.10, line 2.

$D_{t}$ : Net operating surplus, billions of dollars. Table 1.10, line 9.

$R G D P c_{t}$ : Real gross domestic product per capita, chained 2009 dollars. (Via the Federal Reserve Bank of St. Louis FRED database, series ID: A939RX0Q048SBEA).

$G D P_{t}$ : Gross domestic product, billions of dollars. (Via the FRED database, series ID: GDP).

We compute the real per capita labor and capital income series as $w_{t}=\alpha_{t} W_{t}$ and $d_{t}=\alpha_{t} D_{t}$, where $\alpha_{t}=\frac{R G D P c_{t}}{G D P_{t}}$. To remove the long-run growth trend, in the calibration section we use the HP-filtered series $\tilde{w}_{t}$, and $\tilde{d}_{t}$, calculated as the ratios of the cyclical to the trend components of $w_{t}$ and $d_{t}: \tilde{w}_{t}=\frac{w_{t}^{\text {cyclical }}}{w_{t}^{\text {trend }}}$ and $\tilde{d}_{t}=\frac{d_{t}^{\text {cyclical }}}{d_{t}^{\text {trend }}}$.

\section{C.2 Empirical exercises}

Sample countries (151): Afghanistan, Albania, Algeria, Antigua and Barbuda, Argentina, Armenia, Australia, Austria, Azerbaijan, Bahrain, Belarus, Belgium, Belize, Benin, Bhutan, Bolivia, Bosnia and Herzegovina, Botswana, Brazil, Bulgaria, Burkina Faso, Burundi, Cambodia, Cameroon, Canada, Cape Verde, Central African Republic, Chile, China, Colombia, Congo, Dem. Rep., Costa Rica, Cote d'Ivoire, Croatia, Czech Republic, Denmark, Djibouti, Dominica, Dominican Republic, Ecuador, Egypt, El Salvador, Eritrea, Estonia, Ethiopia, Fiji, Finland, France, Gabon, Gambia, Georgia, Germany, Ghana, Greece, Grenada, Guatemala, Guinea-Bissau, Guyana, Honduras, Hong Kong, China, Hungary, Iceland, India, Indonesia, Iran, Iraq, Ireland, Israel, Italy, Jamaica, Japan, Jordan, Kazakhstan, Kenya, Korea, Rep., Kuwait, Kyrgyz Republic, Lao, Latvia, Lebanon, Liberia, Libya, Lithuania, Luxembourg, Macedonia, Malawi, Malaysia, Maldives, Mali, Malta, Mauritania, Mauritius, Mexico, Moldova, Mongolia, Montenegro, Morocco, Mozambique, Namibia, Nepal, Netherlands, New Zealand, Niger, Nigeria, Norway, Pakistan, Papua New Guinea, Paraguay, Peru, Philippines, Poland, Portugal, Qatar, Romania, Russia, Rwanda, Senegal, Serbia, Seychelles, Sierra Leone, Slovak Republic, Slovenia, South Africa, Spain, Sri Lanka, St. Kitts and Nevis, St. Lucia, St. Vincent and the Grenadines, Sweden, Switzerland, Syria, Tajikistan, Tanzania, Thailand, Togo, Tonga, Trinidad and Tobago, Tunisia, Turkey, Uganda, Ukraine, United Kingdom, United States, Uruguay, Uzbekistan, Vanuatu, Venezuela, Vietnam, Yemen, Zambia, Zimbabwe. ${ }^{17}$

The four measures of capital stocks are taken from the External Wealth of Nations Mark II database, Lane and Milesi-Ferretti (2007). All data are for the year 2010, reported in billions of current U.S. dollars.

Gross holdings of assets and liabilities $(G A L)$ is the sum of total assets and total liabilities of each country. Total assets is the sum of FDI assets, portfolio equity assets, and

\footnotetext{
${ }^{17}$ Due to missing observations, the total number of countries in our regression dropped to 110.
} 
debt assets plus FX reserves minus gold. Total liabilities are calculated analogously.

Net Equity $(N E)$ is calculated as portfolio equity assets + FDI assets - portfolio equity liabilities - FDI liabilities.

Net Debt $(N D)$ is computed as Debt assets (portfolio debt + other investment) - Debt liabilities (portfolio debt + other investment).

Net Foreign Assets (NFA) measures the difference between a country's total assets and total liabilities.

PSgdp: Total public pension spending as a percent of GDP. World Bank HDNSP pensions database, data for the most recent available year, ranging from 2000 (Iran) to 2012 (Colombia, Malawi, Malaysia, Mexico, Moldova, Peru, Qatar, Tunisia).

GDPcP PP: GDP per capita based on purchasing power parity, current international dollars, 2010. World Bank DataBank, series code NY.GDP.PCAP.PP.CD.

Population $(P O P)$ : Total population, 2010. World Bank DataBank, series code SP.POP.TOTL.

Pension Spending $(P S)$ : Total pension spending, billions of current international dollars. Calculated as $P S g d p \times G D P c P P P \times P O P \times 10^{-9}$.

GDP adjusted for PPP (GDPppp): Total GDP based on purchasing power parity, billions of current international dollars. Calculated as $G D P c P P P \times P O P \times 10^{-9}$.

Life Expectancy ( $L E m, L E w)$ : Life expectancy at birth, years (data for men and women), 2009/2010. Social Security Administration "Social Security Programs Throughout the World."

Contributions $(C O N T)$ : Contribution rates for old age, disability, and survivors social security programs (percent of earnings), 2009/2010. Social Security Administration "Social Security Programs Throughout the World."

Retirees $(R E T c)$ : Number of people aged 65 and older relative to total population, 2010. World Bank HDNSP pensions database.

Coverage $(C O V)$ : Pension system coverage, defined as the total number of active contributors relative to the working age population, 2013. World Bank HDNSP pensions database.

The index of financial freedom (HFI): "Financial freedom is a measure of banking efficiency as well as a measure of independence from government control and interference in the financial sector. State ownership of banks and other financial institutions such as insurers and capital markets reduces competition and generally lowers the level of available services. The Index scores an economy's financial freedom by looking into the following five broad areas: the extent of government regulation of financial services; the degree of state intervention in banks and other financial firms through direct and indirect ownership; the extent of financial and capital market development; government influence on the allocation of credit; and openness to foreign competition." Heritage Foundation Index of Economic Freedom, data for 2010. We collapse the data into five categories, ranging in value from 1 to 5, by combining the adjacent levels of government interference: thus, a value of 1 (original index levels of 10 through 20) now represents repressive governments, while a value of 5 (original index levels of 90 through 100) is assigned to countries with very low levels of government interference in the market. Index of Economic Freedom, available online at http://www.heritage.org/index.

Trade Volume $(V O L)$ : the sum of a country's imports and exports of goods and services, measured in billions of current U.S. dollars, 2010. World Bank DataBank (series 
Table 8: Descriptive statistics

\begin{tabular}{lccccc}
\hline \hline & Mean & Std. Dev. & Min & Max & Obs \\
\hline Panel A: Dependent Variables & & & & & \\
Net Equity $(N E)$ & -10.35 & 314.53 & -1481.44 & 3004.39 & 151 \\
Net Debt $(N D)$ & -61.26 & 543.54 & -5853.74 & 1567.82 & 151 \\
Net Foreign Assets $(N F A)$ & -32.80 & 385.73 & -2617.58 & 2884.83 & 151 \\
\hline & & & & & \\
Panel B: Control Variables & & & & & \\
Total pension spending, PPP $(P S)$ & 2906.93 & 10206.41 & 0.0009 & 101716.40 & 147 \\
GDP, PPP $(G D P p p p)$ & 501.05 & 1544.28 & 0.46 & 14958.40 & 147 \\
Life expectancy, men $(L E m)$ & 68.43 & 8.84 & 47.20 & 80.80 & 134 \\
Life expectancy, women $(L E w)$ & 73.34 & 9.97 & 49.70 & 87.20 & 134 \\
Contribution rates $(C O N T)$ & 15.70 & 8.73 & 0.00 & 38.50 & 132 \\
Financial Freedom Index $(H F I)$ & 2.86 & 0.99 & 1 & 5 & 146 \\
CEES dummy $(C E E S)$ & 0.21 & 0.62 & 0 & 1 & 151 \\
Net exports of oil $(O I L)$ & -0.0006 & 0.26 & -0.96 & 2.17 & 151 \\
Volume of trade $($ VOL $)$ & 204.68 & 496.49 & 0.20 & 4191.73 & 145 \\
OPEC dummy $(O P E C)$ & 0.06 & 0.24 & 0 & 1 & 151 \\
Retirees/Population $(R e t P o p)$ & 7.99 & 5.38 & 1.04 & 21.95 & 151 \\
Pension coverage $(C O V)$ & 0.33 & 0.26 & 0.004 & 0.94 & 136 \\
Population $(P O P), \log$ & 15.88 & 1.92 & 10.83 & 20.99 & 151 \\
\hline \hline
\end{tabular}

The three dependent variables, total pension spending, GDP, and the volume of trade are measured in billions of current dollars (either U.S. or international). Net oil exports are measured in billions of barrels per day.

BX.GSR.GNFS.CD for exports, series BM.GSR.GNFS.CD for imports).

CEEC Indicator $(C E E C)$ : Dummy variable identifying the countries in the Central and Eastern Europe and post-communist block categories: Albania, Belarus, Bosnia and Herzegovina, Bulgaria, Croatia, Czech Republic, Estonia, Hungary, Latvia, Lithuania, Macedonia, Moldova, Montenegro, Poland, Romania, Russia, Serbia, Slovak Republic, Slovenia, and Ukraine.

OPEC $(O P E C)$ : Dummy variable identifying the member countries of the OPEC group: Algeria, Ecuador, Iran, Iraq, Kuwait, Libya, Nigeria, Qatar, and Venezuela.

Oil Exports $(O I L)$ : Total exports less total imports of refined petroleum products, billions of barrels per day, 2010. U.S. Energy Information Administration (www.eia.gov) International Energy Statistics.

Notes: Missing RetPop data for Antigua and Barbuda, Dominica, Seychelles, and St. Kitts and Nevis are taken from the Social Security Administration "Social Security Programs Throughout the World," 2009/2010. 